\title{
The COVID-19 Pandemic and the 2020 U.S. Presidential Election*
}

\author{
Leonardo Baccini
}

Abel Brodeur

November 9, 2020

\author{
Stephen Weymouth
}

\begin{abstract}
What is the effect of the COVID-19 pandemic on the 2020 U.S. presidential election? Guided by a pre-analysis plan, we estimate the effect of COVID19 cases and deaths on the change in county-level voting for Donald Trump between 2016 and 2020. To account for potential confounders, we include a large number of COVID-19-related controls as well as demographic and socioeconomic variables. Moreover, we instrument the numbers of cases and deaths with the share of workers employed in meat-processing factories to sharpen our identification strategy. We find that COVID-19 cases negatively affected Trump's vote share. The estimated effect appears strongest in urban counties, in swing states, and in states that Trump won in 2016. A simple counterfactual analysis suggests that Trump would likely have won re-election if COVID-19 cases had been 5 percent lower. Our paper contributes to the literature of retrospective voting and demonstrates that voters hold leaders accountable for their (mis-)handling of negative shocks.
\end{abstract}

KEYWORDS: COVID-19, pandemic, elections, political behavior, pre-analysis plan.

JEL CLASSIFICATIONS: D72, I18.

\footnotetext{
*Baccini: Associate professor of political science at McGill University. E-mail: leonardo.baccini@mcgill.ca. Brodeur: Associate professor of economics at University of Ottawa. E-mail: abrodeur@uottawa.ca. Weymouth: Associate professor and Awad Fellow, McDonough School of Business, Georgetown University. E-mail: stephen.weymouth@georgetown.edu. Funding for this research was provided by the Internal McGill COVID-19 Rapid Response for Social Sciences and Humanities Grant. We would like to thank Sean Nossek, Paul-Antoine Seitz, and Taylow Wright for excellent research assistance. Leo Baccini acknowledges the support of the Hoover Institution at Stanford University, where he is a national fellow for the 2020-21 academic year. Corresponding author: Leo Baccini. This version relies on data of election results up to November 8, 2020, at 8pm (EST). We will update the paper using complete election results when they are available.
} 


\section{Introduction}

The COVID-19 pandemic is among the most consequential global events since World War II, affecting virtually every country in the world. By the end of October 2020, more than 40 million people had contracted the virus and over one million had died. In response to the pandemic, governments restricted citizens' movement to varying degrees through lockdown measures, with the objective of slowing the spread of the disease. The pandemic contributed to severe economic contractions in most countries, increasing unemployment and poverty around the world.

In the U.S., the COVID-19 pandemic struck during a presidential election year, shifting the political narrative and President Trump's reelection prospects. Prior to the pandemic, the U.S. economy was performing well, and Trump, while extremely polarizing, enjoyed strong support among Republican voters. The virus changed the narrative, and Trump's response was widely criticized. He consistently downplayed the risks of the disease, refused to embrace basic health precautions such as masks, and repeatedly criticized epidemiologists and scientists, including those advising him. Trump's pandemic response, which contrasted with those of leaders in other developed democracies, was unsuccessful. As of the end of October, the U.S. had suffered the largest numbers of cases (over 8 million) and deaths (over 220,000) in the world.

In this paper, we explore the effect of the COVID-19 pandemic on the 2020 U.S. presidential election. We investigate whether Trump's electoral support was reduced in localities hit harder by the pandemic. Guided by a pre-analysis plan (PAP), we constructed a data set at the county level, with the difference in vote share for President Trump between the 2020 and 2016 presidential elections as our dependent variable. ${ }^{1}$ Our main independent variable is COVID-19 cases and deaths, which we gather from the data compiled by the Center for Systems Science and Engineering at Johns Hopkins University, and statewide policies such as stayat-home orders and mandatory wearing of face masks. In our estimates, we control for social distancing and four occupational measures: (1) exposure to disease or infection, (2) physical proximity, (3) essential worker designation, and (4) remote work. In addition, we account for demographic and socioeconomic variables and for unemployment changes, August 2019-August 2020. In placebo tests, we show that COVID-19 incidence is uncorrelated with changes in Republican candidates vote share in previous elections, e.g., votes for Trump in 2016 compared with votes for Romney in 2012.

In an attempt to sharpen our identification strategy, we instrument COVID-19

\footnotetext{
${ }^{1}$ The pre-analysis plan was posted and registered on October 30, 2020: https://osf.io/ xvuzp/. See Appendix for more details.
} 
cases with the share of workers employed in meat-processing factories. We show that counties with a larger share of workers employed in meat-processing factories experienced a significantly larger number of cases than counties with a smaller share of workers employed in meat-processing factories. Our two-stage least squares estimates also control for the share of manufacturing in each county in an effort to validate the exclusion restriction.

Our results indicate that COVID-19 cases have had a significant negative effect on the Trump vote share in the 2020 presidential election (in comparison to 2016). This finding holds in both the reduced form analysis and the instrumental variable analysis. We also find potentially important effect heterogeneity. In particular, the negative impact of COVID-19 incidence on President Trump's support is stronger (1) in states that Trump won in the 2016 presidential election, (2) in swing states, and (3) in urban counties. We find no evidence that worsening economic conditions reduce electoral support for President Trump or that COVID-19 cases affect voters' mobilization, measured as the number of votes cast in 2020 compared to 2016.

These effects not only are significant and robust to a many robustness checks, but they are also quite sizable. A simple counterfactual exercise shows that, ceteris paribus, if the number of COVID-19 cases had been 5 percent lower, Trump would have won the following states: Arizona, Georgia, Pennsylvania, and Wisconsinlikely resulting in his reelection.

Our paper is related to several streams of the literature on political behavior and political economy. ${ }^{2}$ First, our paper speaks to the literature of retrospective voting, which examines how citizens evaluate and vote based on their perceptions of the incumbent's performance (Fiorina 1981, Ferejohn 1986, Persson and Tabellini 1997, Fearon 1999, Canes-Wrone and Shotts 2001, Ashworth 2012). Our findings indicate that voters assess the competence of political leaders in the case of a pandemic and hold them accountable for rising numbers of cases and deaths.

Second, our paper is related a literature that links natural disasters to political behavior (Abney and Hill 1966, Chen 2012, Malhotra and Kuo 2008, Abney and Hill 1966). The logic of this literature is similar to that of retrospective voting. Rational voters reward incumbents not only for delivering a positive economic performance in good times, but also for organizing prompt rescue and relief programs in bad times, such as in the aftermath of extreme weather events. Our findings indicate that incumbent governments are punished electorally for failing to provide effective mitigation and relief, even if the primary shock (in this case, a virus) is not directly attributable to them.

Third, our paper speaks to the literature on the effect of personally experiencing shocks (e.g. crises and wars) on political and social attitudes (Lau and Sears 1978,

\footnotetext{
${ }^{2}$ For an excellent review of this literature, see Healy and Malhotra (2020).
} 
Kinder and Kiewiet 1981, Erikson and Stoker 2001, Mo and Conn 2018). Our findings are consistent with studies showing that negative economic shocks increase support for government intervention in the economy and redistributive policies as well as people's beliefs about the relative importance of luck versus effort (Margalit 2013, Giuliano and Spilimbergo 2014). These changes in voters' preferences and beliefs are consistent with increasing support for a Democratic candidate over an incumbent Republican president in the midst of a pandemic.

\section{The COVID-19 Pandemic and the U.S. Presidential Election}

News of a novel coronavirus made global headlines beginning in January 2020. On January 9, 2020 the World Health Organization announced a coronavirus-type pneumonia outbreak in Wuhan, China. The U.S. Centers for Disease Control and Prevention began screening at three major U.S. airports on January 20, and the first U.S. coronavirus case was confirmed the following day. On January 23, China made the unprecedented move of quarantining Wuhan, a city of 11 million people. The White House announced on January 31 a travel ban on foreign nationals who had traveled to China within the past 14 days. The first U.S. death from the disease occurred on February 29 in Washington State. ${ }^{3}$

The WHO declared a pandemic on March 11. That same day the U.S. National Basketball Association suspended all games, and the actor Tom Hanks and his wife Rita Wilson announced they had tested positive for the virus in Australia. President Trump declared a national emergency on March 13, unlocking up to $\$ 50$ billion dollars in federal funding to combat the spread of the disease, the same day on which several states announced school closures. On March 19, California became the first state to issue a "stay-at-home" order, with exceptions for work and shopping for essential needs. On March 26, Trump signed into law the CARES Act, which provided $\$ 2$ trillion in aid to businesses, hospitals, and local governments.

While no country was unaffected, the COVID-19 pandemic hit the U.S. particularly hard. The U.S. COVID-19 death toll passed the grim mark of 100,000 on May 28; by September 22, 200,000 American lives had been lost. Measured on a per capita basis, only Brazil, Spain, and Mexico have recorded higher death rates among large countries. ${ }^{4}$ Along with lost lives, the uncontrolled spread of COVID19 in the U.S. exerted a profound economic impact. Increasing numbers of cases caused changes in consumer behavior, with large drops in consumption of services (Baker et al. Forthcoming, Chetty et al. 2020) leading to an unprecedented increase

\footnotetext{
${ }^{3}$ https://www .ajmc.com/view/a-timeline-of-covid19-developments-in-2020https:// www.nbcnews. com/health/health-news/coronavirus-timeline-tracking-critical-moments - covid-19-n1154341.

${ }^{4}$ https://coronavirus. jhu.edu/data/mortality.
} 
in unemployment (Chetty et al. 2020, Coibion et al. 2020). The economic downturn coincided with changing political attitudes about the role of government, with Rees-Jones et al. (2020a) finding deaths and infections associated with increased support for expanding the U.S. safety net.

In sharp contrast to most world leaders and to his opponent Joe Biden, Trump sought to downplay the threat of the virus, with limited political success. He began this tactic early in the crisis, and never veered from it. On February 10, Trump claimed, "a lot of people think that [coronavirus] goes away in April with the heat..." On February 26, as U.S. cases began to appear, he said, "when you have 15 people, and the 15 within a couple of days is going to be down to close to zero, that's a pretty good job we've done." Again, on April 3 he remarked, "It is going to go away. It is going away." He continued making similar comments throughout the summer, and in his first remarks after contracting the virus himself in October, he declared, "It's going to disappear. It is disappearing." The tactic did little to help his standing with the electorate. According to Gallup, President Trump's approval rating fell from a 2020 high of $49 \%$ on March 22 to $38 \%$ on June $30 .{ }^{6}$ Polls showed nearly $60 \%$ of Americans disapproved of Trump's response to the pandemic, with very little variation in the five months leading up to the election. ${ }^{7}$

There are several reasons to believe that the pandemic, and the Trump administration's response, were detrimental to Trump's reelection prospects. The strong disapproval of the president's handling of the virus suggests that a majority of the public blamed the administration for its failure to curtail its spread. Most importantly, voters likely associate rising local cases and deaths with an increasing threat to the health and safety of themselves and their loved ones. In this context, we might expect that the greater the local exposure to risk, the more likely voters are to punish the president by voting for the challenger. Another channel through which COVID-19 may have lead to diminished Trump support is economic. Despite a big rebound in economic growth in the third quarter of 2020, the unemployment rate remains well above the historical average. Ominously, rising case numbers in the lead-up to the election portended another wave of hospitalizations and deaths - and the prospect of more localized lockdowns, business closures, and a double-dip recession. Both retrospective and prospective voting frameworks suggest that voters are likely to hold the president accountable for the toll of the virus. For these reasons, we examine whether more severe local outbreaks are associated with weaker support for Trump in 2020, compared to the 2016 presidential election.

There is, however, a counter-argument to be made. A possible interpretation

\footnotetext{
${ }^{5}$ https://www.cnn.com/interactive/2020/10/politics/covid-disappearing-trumpcomment-tracker/.

${ }^{6}$ https://news.gallup.com/poll/203207/trump-job-approval-weekly . aspx.

${ }^{7}$ https://projects.fivethirtyeight.com/coronavirus-polls/
} 
of Trump's strategy in responding to the pandemic is that it was in line with the preferences of his core constituents. Survey data reveal a striking difference in attitudes towards the pandemic between Democratic and Republican voters. According to Gallup, only $25 \%$ of Republican respondents are "worried about getting the coronavirus," whereas this percentage climbs to almost $80 \%$ among Democratic respondents. ${ }^{8}$ Similarly, about $60 \%$ of Republican respondents are "ready to return to normal activities right now," whereas a mere $3 \%$ of Democratic respondents are ready to resume a normal lifestyle. We see similar differences for questions related to practicing social distancing, wearing masks, and avoiding large crowds. While ideology influences attitudes toward the pandemic in other countries as well, the differences between Democratic and Republican voters in the U.S. are uniquely large. In short, given the polarization of U.S. politics, voters seem to be experiencing the very same event in very different ways based on their partisan identities. If this is the case, even a global pandemic responsible for hundreds of thousands of deaths may not meaningfully reduce support for President Trump, especially among his base.

The remainder of the paper empirically investigates the effect of COVID-19 on county-level support for Trump in 2020 compared to 2016. The exercise is nontrivial, since partisan identities can influence behavior in ways that may affect COVID-19 cases as well as Trump support - as the partisan differences in attitudes toward the virus reveal. ${ }^{9}$ We address this issue and other possible sources of endogeneity through numerous empirical strategies, which are detailed below.

\section{Data and Empirical Strategy}

We describe all the data that we use in our analysis below.

\section{COVID-19 Data}

Our analysis relies on known COVID-19 cases and deaths, recorded at the county level. We use the COVID-19 incidence data compiled by the Center for Systems Science and Engineering at Johns Hopkins University. The data and data sources at the state and county levels can be accessed here: https://github.com/ CSSEGISandData/COVID-19. The cumulative totals of COVID-19 cases and deaths correspond to October 22, 2020. In our sample, the mean for the cumulative number

\footnotetext{
${ }^{8}$ https://news.gallup.com/opinion/gallup/321698/covid-responses-men-women.aspx [consulted on November 4, 2020].

${ }^{9}$ Indeed, press analyses indicate a positive correlation between COVID-19 cases and Trump's support. See for instance, "Counties with worst virus surges overwhelmingly voted Trump" by AP news, available at https://apnews.com/article/ counties-worst-virus-surges-voted-trump-d671a483534024b5486715da6edb6ebf.
} 
Figure 1: Cumulative Number of COVID-19 Cases per 10,000

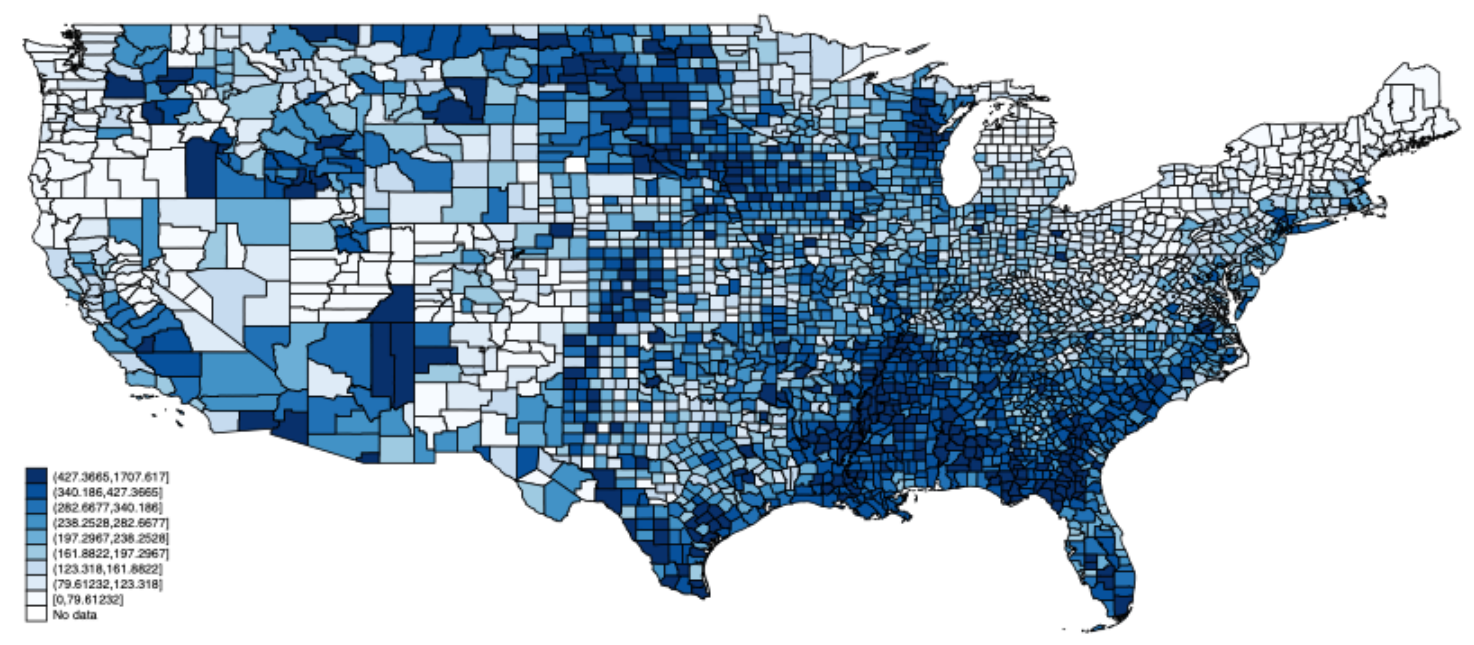

Notes: This figure illustrates the the cumulative number of COVID-19 cases per 10,000 as of October 22, 2020.

of COVID-19 cases per 10,000 is 245 (std. dev. 162), while the cumulative number of COVID-19 deaths per 100,000 is 52 (std. dev. 59). Figure 1 and Appendix Figure A1 illustrate the distribution of cases and deaths in the U.S., respectively.

We also gather data on the following COVID-19 policies: stay-at-home orders, mandatory face mask policies, day care closures, freezes on evictions, and mandated quarantine for individuals arriving from another state. Data on policy duration are drawn from Raifman et al. (2020). See the Appendix for more details.

We draw social distancing data from Google's COVID-19 Community Mobility Reports. This data set captures visits to a location relative to a baseline day using data from users who have enabled "location history" in their Google account. The baseline day is the median value for the 5 -week period from January 3 to February 6, 2020. We rely on workplace as the location of interest as of April 1, 2020, i.e., the midpoint of the first COVID-19 wave. We also rely on mobility change as of August 1st as a robustness check, i.e., the midpoint of the second wave. ${ }^{10}$

\section{Election Data}

We merge variables capturing COVID-19 incidence by county, with data on countylevel election results from Dave Leip's Atlas of U.S. Presidential Elections. ${ }^{11} \mathrm{We}$ compute the difference of vote shares of President Trump between the 2020 and 2016 U.S. presidential elections. Specifically, we compute shares dividing the total number of votes for Trump by the total number of votes in each county.

\footnotetext{
${ }^{10}$ See Brodeur, Gray, Islam and Bhuiyan (2020) for a review of studies using cellphone data to measure mobility during the pandemic.

${ }^{11}$ Data can be purchased from https://uselectionatlas.org/BOTTOM/store_data.php.
} 
Table 1 provides summary statistics, whereas Figure 2 illustrates changes in voting share from 2016 to 2020. The map shows that Trump's support fell in parts of the Rust Belt and the Sun Belt in 2020, when compared with the 2016 presidential election. $^{12}$

Table 1: Descriptive Statistics

\begin{tabular}{lccccc}
\hline \hline & & & & & \\
& Mean & S. D. & Max & Min & $n$ \\
& & & & & \\
Election Outcomes & & & & & \\
Trump Voting (2020) & 63.9 & 15.4 & 92.4 & 8.89 & 2,586 \\
Changes in Trump Voting (2020-2016) & 1.87 & 2.72 & 28.11 & -7.23 & 2,586 \\
Changes in Total Votes (2020-2016) & 4,740 & 23,136 & 477,918 & $-353,229$ & 2,586 \\
& & & & & \\
COVID-19 Incidence & 3,050 & 10,891 & 290,486 & 0 & 2,586 \\
Cum. COVID-19 Cases & 244 & 155 & 1,708 & 0.0 & 2,586 \\
Cum. COVID-19 Cases per 10,000 & 80 & 338 & 7,374 & 0 & 2,586 \\
Cum. COVID-19 Deaths & 51 & 53 & 524 & 0.0 & 2,586 \\
Cum. COVID-19 Deaths per 100,000 & & & & & \\
& 0.014 & 0.053 & 0.585 & 0.0 & 2,586 \\
Labor Outcomes & 2.88 & 1.83 & 18.6 & -5.0 & 2,586 \\
Share Emp. Meat Factories & & & & & \\
Unemployment Rate Change & & & & & \\
&
\end{tabular}

Notes: Authors' calculations. Election results from Dave Leip's Atlas of U.S. Presidential Elections. Cumulative COVID-19 cases, cases per 10,000 people, deaths, and deaths per 100,000 people are the cumulative totals corresponding to October 22, 2020. Share of employment in meat-processing factories is computed using data from the County Business Patterns. Monthly unemployment data comes from the Bureau of Labor Statistics' Local Area Unemployment Statistics.

\section{Economic Data}

Employment Data We rely on the County Business Patterns (CBP) to compute the share of employment in meat-processing factories. ${ }^{13}$ The CBP provides annual data for establishments with paid employees within the U.S. This data set provides annual employment data at the county level for the week of March 12 and annual payroll data. Note that the CBP does not include employment for most establishments with government employees and the following NAICS industries: crop and animal production; rail transportation; Postal Service; pension, health, welfare, and vacation funds; trusts, estates, and agency accounts; office of notaries; private households; and public administration. See https://www . census . gov/programs-surveys/cbp/about.html for more details.

\footnotetext{
${ }^{12}$ Appendix Figures A2 and A3 illustrate the share of votes for the Trump in the 2020 and 2016 presidential elections.

${ }^{13}$ Appendix Figure A5 illustrates the share of employment in meat-processing factories.
} 
Figure 2: Changes in Share of Votes for Donald Trump from 2016 to 2020

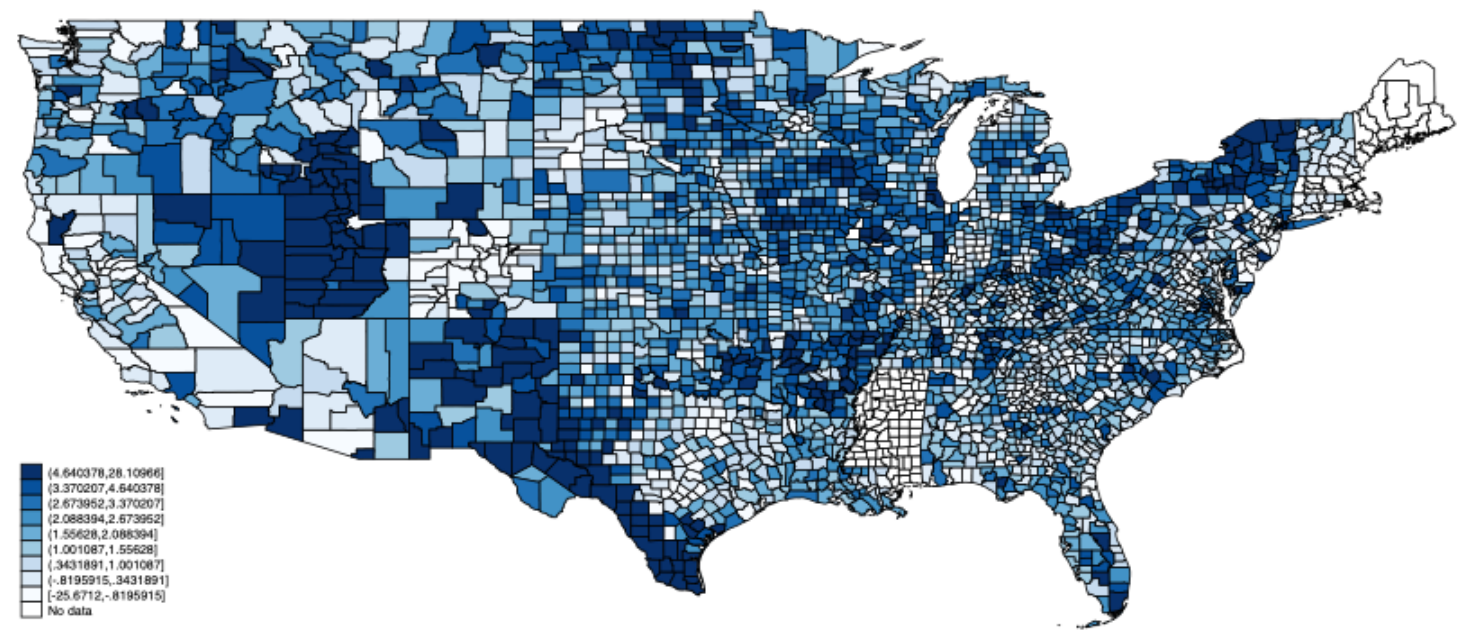

Notes: This figure illustrates the differential in vote shares for Trump in 2020 and 2016.

Last, we get monthly unemployment rates at the county level from the U.S. Bureau of Labor Statistics' Local Area Unemployment Statistics. In our sample, the mean change in the unemployment rate from August 2019 to August 2020 was an increase of 2.69. ${ }^{14}$ Appendix Figure A4 illustrates the geographical distribution for this variable.

\section{Occupational Measures}

We rely on four occupational indexes as control variables: (1) exposure to disease or infection, (2) physical proximity, (3) essential worker designation, and (4) remote work. The first three indexes were built in Beland et al. (2020), while the remote work index comes from Dingel and Neiman (2020). These indexes serve as covariates in our analysis since they have been shown to be related to the severity of job losses in the U.S. and could be related to voting behavior and COVID-19 incidence. See the Appendix for more details on these four indexes.

\section{Empirical Strategy}

In this section, we describe the empirical strategy that was pre-specified in a PAP. We first present our OLS model and provide evidence that our model is more appropriate than a naïve model relating COVID-19 incidence and Trump vote share. We then describe the IV specification, in which we instrument COVID-19 incidence with the share of employment in meat-processing plants.

\footnotetext{
${ }^{14}$ The increase in the unemployment rate was much larger during the months of April and May 2020. Also note that the increase in unemployment does not include workers who are currently employed but are not working due to lockdowns. See Beland et al. (2020) for a discussion.
} 


\section{COVID-19 Incidence: OLS}

As stated in our PAP, we first rely on the following model:

$$
\Delta Y_{c}=\alpha+\beta C O V I D \text { Incidence }_{c}+X_{c}^{\prime} \gamma+\theta_{s}+\varepsilon_{c},
$$

where $Y_{c}$ is the differential in Trump's vote share in 2020 and 2016 for county $i$. COVID Incidence $_{c}$ is the cumulative number of confirmed COVID-19 cases per 10,000 inhabitants or COVID-19 deaths per 100,000 inhabitants as of October 22, $2020{ }^{15}$ We report standard errors clustered at the state level.

We include in the model $X_{c}$, which is a vector of county-level variables. We include the following demographic and socioeconomic variables: population, share of female population, share of foreign-born population, share of population with a college degree, share of non-Hispanic Black population, share of non-Hispanic White population, share of population by age group (9 dummies), social mobility index, and four occupational indexes. Moreover, we compute employment changes due to the pandemic at the county level by taking the unemployment rate as of September 2020 minus the unemployment rate as of September 2019. ${ }^{16}$ The inclusion of these variables allows us to relax our identification assumption that no omitted variables are related to COVID-19 incidence and the change in voting behavior from the 2016 to the 2020 presidential election. Finally, $\theta_{s}$ represents state fixed effects. This set of fixed effects allows us to further control for county-level characteristics that are common to counties within the same state.

Our estimation is thus at the county level and we effectively test whether counties with relatively more COVID-19 cases or deaths differentially voted for the Trump in 2020 compared with the previous presidential election. We use this model instead of a model relating COVID-19 incidence to vote share in 2020 alone to better capture trends in voting behavior. In other words, we compare how voting behavior changed pre- and post-COVID-19 rather than simply analyzing voting behavior post-COVID-19. We believe this is crucial in this context given the increasing political polarization in the U.S. Moreover, we think that the inclusion of state fixed effects and controlling for social distancing and a large set of demographic variables helps account for differential (changes in) behavior and preferences across counties. This is also crucial because a growing literature has shown, for instance, that indi-

\footnotetext{
${ }^{15}$ We follow our PAP in using October 22, 2020 for calculating the number of COVID-19 cases. Nonetheless, we check the robustness of our results using other dates for calculating the number of COVID-19 cases. See the Results section for more details.

${ }^{16}$ Relying on different months for the before and during COVID-19 periods has no effect on our conclusion that job losses are not related to differential voting behavior from the 2016 to the 2020 elections. On average, the unemployment rate from September 2019 to September 2020 increased by 2.69 percentage points in our sample (std. dev. 1.86).
} 
viduals identifying as Republicans are less likely to comply with social distancing orders than those identifying as Democrats (e.g., Allcott et al. (2020); Gollwitzer et al. (2020)).

In Appendix Table A1, we provide empirical evidence that COVID-19 incidence is significantly related to votes for Trump in 2016 and 2020. We then provide evidence that COVID-19 incidence in our model is not successfully predicting changes in voting behavior for previous presidential elections. The variables of interest are the cumulative number of COVID-19 cases per 10,000 (columns 1-3) and COVID19 deaths per 100,000 (columns 4-6). In Panel A (B), the dependent variable is the vote share for Trump in the 2020 (2016) presidential election, whereas the dependent variable in Panel $\mathrm{C}$ is the change in votes for Trump from 2012 to 2016 . Columns 1 and 4 include only state fixed effects and our demographic controls, while columns 2 and 3 sequentially add socioeconomic controls and our social distancing indicator.

The estimates in Panels A and B are positive and significant, suggesting that counties with more Trump's supporters had larger numbers of COVID-19 cases. The fact that both estimates are positive and significant for both the 2016 and the 2020 presidential elections suggest that this model is misspecified and that a naïve estimation would conclude that COVID-19 incidence helped Trump during the 2020 presidential election. In contrast, the estimates are small and statistically insignificant in all columns in Panel C. These results provide evidence that our empirical model is properly specified.

\section{COVID-19 Incidence: IV}

We complement the reduced form analysis with an instrumental variable approach. The concern we attempt to address is that COVID-19 cases and COVID-19 deaths do not occur at random, but rather they correlate with individuals' behavior, which may be different between those who vote for the Democratic Party and those who vote for the Republican Party. For instance, it may be that voters living in "red" (i.e., Republican-leaning) counties are less likely to observe social distancing or to wear masks. If this is the case, this type of behavior would be likely to increase the number of COVID-19 cases (and in turn COVID-19 deaths) and we would observe a larger share of votes for Trump than for Biden in the same counties. While we control for social distancing in the previous analysis, we may have missed some other confounders in our analysis.

To attempt to achieve exogenous variation of COVID-19 cases and deaths at the county level, we instrument COVID-19 cases and deaths with the share of employment in meat-processing factories in each county. More specifically, we use the average number of workers in industry code 3116, "Animal Slaughtering and 
Processing," in each county between 2012 and 2016, i.e., before Trump's presidency. We divide this number by the average number of total workers in each country during the same time frame, i.e., 2012-2015. Data come from the CBP and measure raw employment.

The rationale for the instrument is that there is evidence of meat-processing plants becoming COVID-19 hotbeds due to their cold, humid environment and difficulties with workplace physical distancing. ${ }^{17}$ According to a CDC report on July 10, among 23 states reporting COVID-19 outbreaks in meat and poultry facilities, 16,233 cases in 239 facilities occurred, including 86 (0.5\%) COVID-19 related deaths. ${ }^{18}$ Based on cases reported by Johns Hopkins University, as of May 6, counties containing or within 15 miles of one or more meatpacking plants reported 373 COVID-19 cases per 10,000 residents. That is roughly double the U.S. average of 199 cases per 100,000 in all counties with reported cases. ${ }^{19}$ The severity of the incidence of COVID-19 cases in meat-processing facilities prompted research on how to control the spread of the virus in these plants. ${ }^{20}$

Armed with this instrument, we estimate:

$$
\left\{\begin{array}{l}
C O V I D_{c}=\rho+\phi \cdot M E A T_{c}+X_{c}^{\prime} \psi+\theta_{s}+\nu_{c} \\
\Delta Y_{c}=\alpha+\delta C O \hat{V} I D_{c}+X_{c}^{\prime} \gamma+\theta_{s}+\varepsilon_{c},
\end{array}\right.
$$

where $M E A T_{c}$ is the share of workers in meat-processing plants. We run a first stage in which we regress this variable on the cumulative number of COVID-19 cases per 10,000 inhabitants or deaths per 100,000 inhabitants at the county level, including all controls and state fixed effects as in equation 1. Then we plug in the predicted values of this first stage and estimate the second stage of the 2SLS.

The identifying variance is the industrial composition of each county, specifically the presence of a meat-processing factories. In order for our instrument to allow a causal interpretation, employment in meat-processing factories must only affect the change in voting behavior from 2016 to 2020 through its effect on COVID-19 cases and deaths. To relax this assumption, we control for the share of manufacturing employment as well as share of employment in the specific 2-digit manufacturing industry to which "Animal Slaughtering and Processing" belongs.

Appendix Figures A6 and A7 illustrate the relationship between the cumulative number of COVID-19 cases and deaths and the share of employment in meat-

\footnotetext{
${ }^{17}$ https://www.cnn.com/2020/06/27/health/meat-processing-plants-coronavirus-intl/ index.html [consulted on October 5, 2020].

${ }^{18}$ https : //www.cdc.gov/mmwr/volumes/69/wr/mm6927e2.htm [consulted on October 5 2020].

${ }^{19}$ https : / /www.ewg.org/news-and-analysis/2020/05/ewg-map-counties-meatpacking-1 plants-report-twice-national-average-rate [consulted on October 5 2020].

${ }^{20}$ https : / www . thepigsite.com/news/2020/09/new-research-to-mitigate-covid-19-in\ -us-meat-and-poultry-processing-facilities [consulted on October 5, 2020].
} 
processing factories since the beginning of the pandemic for the (1) top $1 \%$ of counties with the highest share of employment in meat-processing factories, (2) top 5\% of counties with the highest share of employment in meat-processing factories, (3) counties with at least one job in meat-processing factories, and (4) counties without any jobs in meat-processing factories. These figures provide direct evidence that counties with a higher share of employment in meat-processing factories had a higher incidence of COVID-19 during the entire pandemic. COVID-19 case and death incidences are much larger for counties with a relatively high share of employment in meat-processing factories and much smaller for counties with no employment or positive employment share. This result suggests our first stage is strong and that the relationship between the share of employment in meat-processing factories and COVID-19 incidence is non-linear.

Last, we note that the correlation between our instrument and the share of manufacturing employment is 0.3 , whereas the correlation between our instrument and the other controls is never higher than 0.1. Moreover, the raw correlation between COVID-19 cases and deaths and our instrument is 0.3 and 0.1 , respectively. The correlation between COVID-19 cases and deaths and our instrument conditional on controls and state fixed effect is much higher, i.e., above 0.5 for cases and 0.3 for deaths.

\section{Results}

\section{OLS and 2SLS Estimates}

In this section we estimate the effect of COVID-19 incidence on voting behavior using OLS and 2SLS. We focus on COVID-19 cases in the main analysis. We note again that our analysis and choice of control variables was fully detailed in our preanalysis plan. Table 2 contains OLS estimates of equation (1) (columns 1-3). The sample size is 2,586 observations (i.e., counties). ${ }^{21}$ The dependent variable is the differential in vote for Donald Trump in 2020 and 2016. A positive value indicates that Trump received more votes in 2020 than in 2016. We report standard errors clustered at the state level. The variables of interest are the cumulative numbers of COVID-19 cases per 100,000 inhabitants. See Appendix Table A3 for COVID-19 deaths.

What clearly emerges is that COVID-19 cases are negatively related to votes for Trump during the 2020 presidential election in comparison to the 2016 election. In column 1, we include state fixed effects and our set of demographic and socioe-

\footnotetext{
${ }^{21}$ We lose about 400 observations (i.e., counties) because of lack of data for our social distancing indicator. Excluding this control variable and doing the analysis on the full set of counties has no effect on our main conclusions.
} 
Table 2: The Impact of COVID-19 Cases: OLS and 2SLS Estimates

\begin{tabular}{|c|c|c|c|c|c|c|}
\hline Panel A: First Stage & & & & \multicolumn{3}{|c|}{$\begin{array}{c}\text { Cumulative COVID Cases } \\
(5)\end{array}$} \\
\hline $\begin{array}{l}\text { Share Workers } \\
\text { Meat Plants }\end{array}$ & & & & $\begin{array}{l}371.17^{* * *} \\
(84.08)\end{array}$ & $\begin{array}{c}327.06^{* * *} \\
(84.82)\end{array}$ & $\begin{array}{c}318.03^{* * *} \\
(79.84)\end{array}$ \\
\hline \multirow[t]{2}{*}{ Panel B: OLS and 2SLS } & \multicolumn{6}{|c|}{$\begin{array}{l}\text { Change in Trump Vote } \\
\text { from } 2016 \text { to } 2020\end{array}$} \\
\hline & $(1)$ & $(2)$ & $(3)$ & $(4)$ & $(5)$ & $(6)$ \\
\hline $\begin{array}{l}\text { Cumulative COVID } \\
\text { Cases per } 10,000\end{array}$ & $\begin{array}{l}-0.0013^{*} \\
(0.0007)\end{array}$ & $\begin{array}{l}-0.0013^{*} \\
(0.0007)\end{array}$ & $\begin{array}{l}-0.0012^{*} \\
(0.0007)\end{array}$ & $\begin{array}{c}-0.0108^{* * *} \\
(0.0038)\end{array}$ & $\begin{array}{c}-0.0120^{* * *} \\
(0.0043)\end{array}$ & $\begin{array}{r}-0.0123^{* * *} \\
(0.0041)\end{array}$ \\
\hline Unemp. Change & & & $\begin{array}{c}0.0078 \\
(0.0845)\end{array}$ & & & $\begin{array}{l}-0.0397 \\
(0.0586)\end{array}$ \\
\hline State FE & Yes & Yes & Yes & Yes & Yes & Yes \\
\hline Share Manufacturing & & & & Yes & Yes & Yes \\
\hline Demo. Controls & Yes & Yes & Yes & Yes & Yes & Yes \\
\hline Socioecon. Controls & Yes & Yes & Yes & Yes & Yes & Yes \\
\hline Social Distancing & & Yes & Yes & & Yes & Yes \\
\hline Observations & 2,586 & 2,586 & 2,586 & 2,586 & 2,586 & 2,586 \\
\hline F-Statistics & & & & 72.10 & 55.03 & 51.34 \\
\hline
\end{tabular}

Notes: Election data from Dave Leip's Atlas of US Presidential Elections. An observation is a county. Robust standard errors are in parentheses, adjusted for clustering by state. We present OLS estimates in columns 1-3 of specification 1. We present the first stage (Panel A) and the 2-stage estimates (Panel B) of specification (2) in columns 4-6 in which we instrument COVID19 incidence in a first stage by the share of employment in processing meat factories. In Panel A, the dependent variable is the cumulative number of COVID-19 cases per 10,000 (columns 46). In Panel B, the dependent variable is the differential in vote for Trump in 2020 and 2016. Demographic controls include population, female population share, foreign-born population, nonHispanic Black population, non-Hispanic White population and the share of the population by age group. Socioeconomic controls include: share of the population with a college degree and four occupational indexes. The Unemployment change variable is the unemployment rate as of September 2020 minus the unemployment rate as of September 2019. Standard errors clustered by state in parentheses $* * * \mathrm{p}<0.01,{ }^{* *} \mathrm{p}<0.05,{ }^{*} \mathrm{p}<0.1$.

conomic controls. We find that a county with 100 more COVID cases per 10,000 people (as compared to others in the same state) reduced its Trump vote share from 2016 to 2020 by an additional 0.13 percentage points on average. The point estimate is (marginally) statistically significant at the $10 \%$ level.

In column 2, we add to the model our indicator of social distancing, i.e., time spent at workplaces in April 2020. Column 3 is our most extensive model specification. We saturate our model with all the previous controls and state fixed effects. In addition, we add to the model the unemployment change from before to during COVID-19. The magnitude of the estimates and statistical significance remain the same.

Of note, the coefficient of unemployment change (August 2019 to August 2020) is 
small and statistically insignificant. ${ }^{22}$ Our results thus provide suggestive evidence that job losses during the pandemic did not have a large effect on voting behavior and that increases in the unemployment rate does not seem to be a major factor behind the negative effect of COVID-19 on the share of votes for Trump.

The coefficients for some of the other control variables are worth discussing (not shown for space consideration). We find that the share of women is strongly negatively correlated to the change in vote share for Trump. Similarly, Trump seems to have lost vote share in counties with a high share of adults aged 25-54.

Our OLS results provide suggestive evidence that the pandemic affected the 2020 presidential election. The main concern with our OLS estimates is that omitted variables could be related to both COVID-19 incidence and differential voting behavior in the 2016 and 2020 presidential elections. We now turn to our instrumental variable strategy.

In Table 2 (columns 4-6), we present the first stage (Panel A) and the twostage estimates (Panel B) of specification (2) in which we instrument COVID-19 incidence in the first stage by the share of employment in meat-processing factories. We control for our usual set of fixed effects and control variables. As shown in Appendix Figures A6 and A7, we find that the share of employment in meatprocessing factories is strongly positively correlated with COVID-19 incidence. The coefficient is always significant and the F-statistics indicate no concern of a weak instrument.

Our second-stage estimates are presented in the bottom panel (columns 4-6). We find that counties with more COVID-19 cases substantially decreased their vote share for Trump in 2020. The 2SLS estimates are larger than the OLS estimates, and suggest that a county with 100 more COVID cases per 10,000 people (as compared to others in the same state) reduced its Trump vote share from 2016 to 2020 by an additional 1.2 percentage point on average. ${ }^{23}$ The point estimates are statistically significant at the $1 \%$ level and robust to the inclusion of our large set of controls and the share of manufacturing employment as well as the share of employment in the specific 2-digit manufacturing industry to which "Animal Slaughtering and Processing" belongs.

\footnotetext{
${ }^{22}$ Using the change in unemployment for different dates does not affect our conclusions. For instance, measuring unemployment during the first wave of COVID-19 (i.e., April 2020) instead of the month of August 2020 leads to similar estimates and has no effect on the magnitude or significance of the COVID-19 cases variable.

${ }^{23}$ There are many plausible explanations for why our 2SLS estimates are larger than our OLS estimates. First, there is a great deal of measurement error in our estimation. Second, we are estimating a local average treatment effect (LATE) with our IV estimation. Voting behavior in counties with relatively more employment in meat-processing factories may be differently affected by the pandemic than counties with no or a small share of employment in this industry. For instance, counties with employment in meat-processing factories are significantly more populous than counties without any jobs in this industry.
} 
So far, our analysis has underscored an important finding: the COVID-19 pandemic costs President Trump votes. But is this effect large enough to have changed the outcome of the 2020 presidential election? To answer this question, we conduct a simple counterfactual exercise to determine the magnitude of the effect by exploring how the composition of votes in a number of closely contested states would have differed if there had been fewer COVID-19 cases. The computation of the counterfactual is based on the coefficient estimate in column 6 of Table 2. For each county, we compute the fraction of total votes that Trump would have received if the number of COVID-19 cases had been $\mathrm{X} \%$ smaller as $-0.0012 \times C O V I D_{c} \times \mathrm{X} \%$ - i.e., the point estimate of the effect of $C O V I D_{c}$ on Trump's vote share from the OLS estimates, the size of each county's measured COVID-19 cases, and the scaling factor $\mathrm{X} \%$. We next multiply this product by the number of total votes in a county to calculate the number of additional votes that Trump would have received in the counterfactual scenario. We then aggregate these county-level votes into state totals.

Table 3 presents the results of this counterfactual analysis. Column 1 shows the actual vote margin in favor of Biden in the 2020 election for a set of closely contested states. The three subsequent columns show counterfactual outcomes had COVID19 cases been $5 \%$ or $10 \%$ or $15 \%$ fewer. Since we find that the COVID incidence decreased Trump's vote share, the counterfactual analyses for fewer COVID-19 cases correspondingly increase Trump's counterfactual vote totals. The results in Table 3 show that, ceteris paribus, Trump would have won Michigan in a counterfactual scenario with $15 \%$ fewer cases. He would have won Arizona, Georgia, Pennsylvania, and Wisconsin, with 5\% fewer COVID-19 cases. Under this counterfactual, Trump would have been reelected.

Table 3: Counterfactual Outcomes in Closely Contested States Won by Biden

\begin{tabular}{|c|c|c|c|c|}
\hline \multirow[b]{2}{*}{ State } & \multirow[b]{2}{*}{ Trump's Gap } & \multicolumn{3}{|c|}{ COVID-19 Cases } \\
\hline & & $5 \%$ Smaller & $10 \%$ Smaller & $15 \%$ Smaller \\
\hline Arizona & $-16,985$ & 63,299 & & \\
\hline Georgia & $-10,353$ & 18,116 & & \\
\hline Michigan & $-146,124$ & 52,932 & 105,865 & 158,797 \\
\hline Pennsylvania & $-42,539$ & 59,660 & & \\
\hline Wisconsin & $-20,510$ & 61,325 & & \\
\hline
\end{tabular}

Note: The computation of the counterfactual is based on the estimate from the OLS model. An increase in per COVID-19 cases reduces Trump's share of vote by 0.0015 percentage points (see columns 1-3 in Table 2). The actual outcome in column 2 reports the margin in favor of Biden in each state. Negative values indicate that Biden won the state in 2020. The reported values in columns 3 and 4 are estimated margins in favor of Trump in the counterfactual scenario of fewer COVID-19 cases. A positive value in columns 3 or 4 larger than the negative value in column 2 implies that Trump would have won the state. 


\section{Effect Heterogeneity}

We investigate heterogeneous effects of COVID-19 on voting in Table 4. Columns 1 and 2, we document the relationship between COVID-19 incidence and the differential in vote for Trump in 2020 and 2016, for Trump's and his opponent Hillary Clinton's states separately. We define states as Trump's or Clinton's using the electoral votes for the 2016 U.S. presidential election. ${ }^{24}$ We find that the negative effect of COVID-19 cases on Trump's vote is driven by those states that he won in the 2016 presidential election (column 1). The magnitude of the coefficient is about $50 \%$ larger than the magnitude of the coefficient in the entire sample. In contrast, the coefficient of COVID-19 cases is small, positive, and not significant in those states that Clinton won in the 2016 presidential election (column 2). ${ }^{25}$

Columns 3 and 4 restrict the sample to swing and non-swing states. ${ }^{26}$ Our results indicate that the negative effect of COVID-19 cases on Trump's vote is almost twice as large in swing states as it is in non-swing states.

Columns 5 and 6 restrict the sample to urban and rural counties, respectively. We define a county as "urban" ("rural") if over (below) $50 \%$ of its population was living in an urban area in 2010 (U.S. Census). Our results show that urban counties drive the negative effect of COVID-19 cases on Trump's vote. Indeed, the effect is negative and significant in the urban sample, whereas it is smaller and statistically insignificant in rural counties. ${ }^{27}$

COVID-19 Deaths We now check whether our results are robust to the use of COVID-19 deaths instead of cases. Appendix Table A3 shows our estimates. We do not find any evidence that COVID-19 deaths are related to changes in voting behavior from the 2016 to the 2020 presidential election with our OLS model. The estimates are all statistically insignificant. For our 2SLS estimates, our first stage is

\footnotetext{
${ }^{24}$ We classify Maine as a blue state. This has no effect on our conclusions.

${ }^{25}$ Of note, the cumulative number of COVID-19 cases per 10,000 inhabitants varies across Trump's states (271) and Clinton's states (166).

${ }^{26} \mathrm{We}$ classify states as swing or non-swing using the NYT classification available at https://www.nytimes.com/interactive/2020/us/elections/ electoral-college-battleground-states.html, consulted on November 2, 2020. We consider swing states as states categorized as tossup and leaning Democratic: Arizona, Florida, Georgia, Iowa, Maine, Michigan, Minnesota, Nebraska, New Hampshire, Nevada, North Carolina, Ohio, Pennsylvania, Texas, and Wisconsin.

${ }^{27}$ In Appendix Table A2, we investigate heterogeneity by county demographic characteristics. We find that negative effect of COVID-19 cases is stronger for countries below the median percentage of residents aged 65 than for counties above the median percentage of residents aged 65 . Our estimates also indicate that the negative effect of COVID-19 cases is stronger in more racially diverse counties (i.e., those with white population shares below the median). Furthermore, our findings show that the negative effect of COVID-19 cases on Trump's vote is driven by less educated counties (i.e., those with a below-median share of residents with college degrees), which may help explain Biden's victory in the Rust Belt.
} 
Table 4: The Impacts of COVID-19 Cases (2SLS): Heterogeneity Analyses by State and County Characteristics

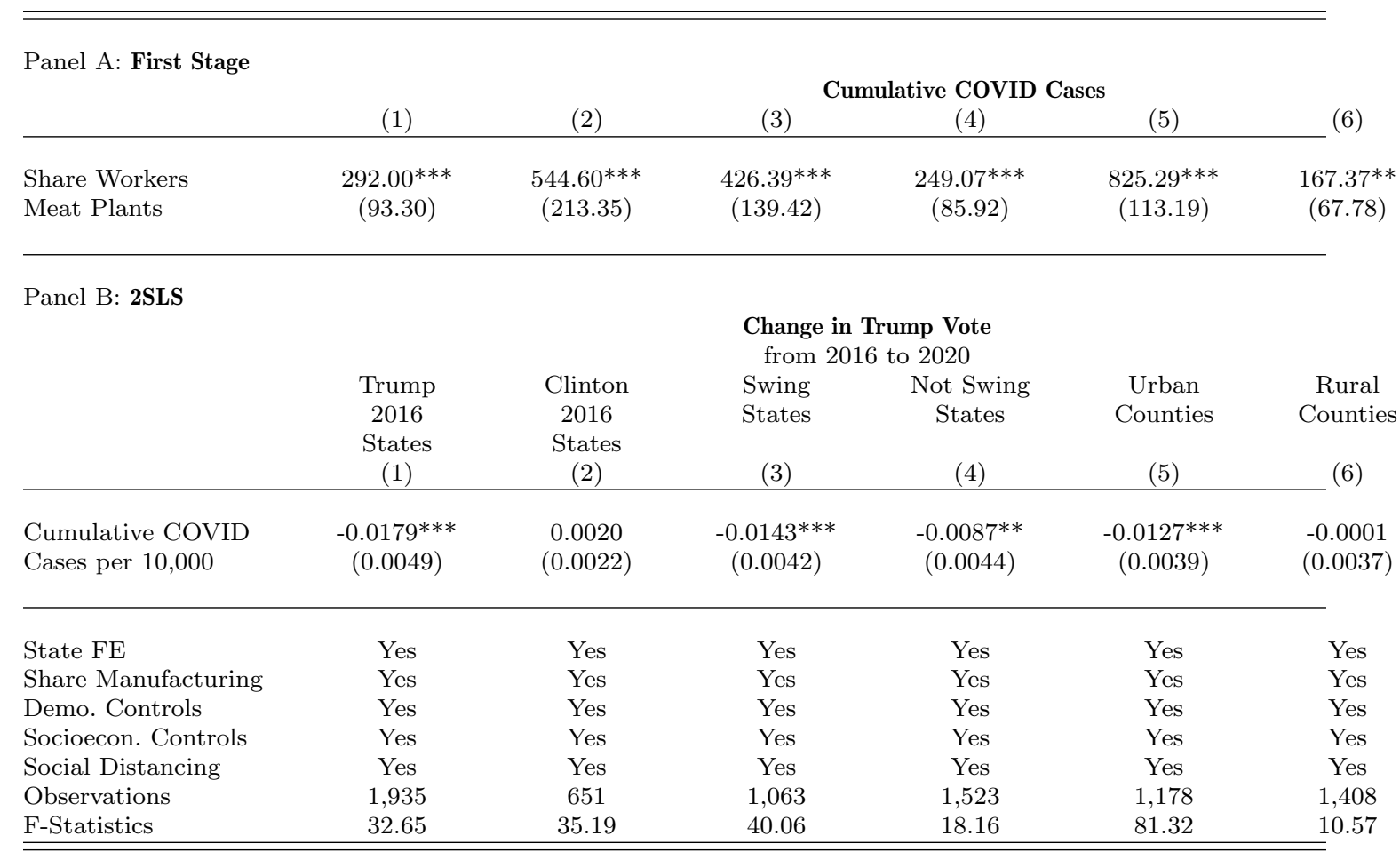

Notes: Election data from Dave Leip's Atlas of US Presidential Elections. An observation is a county. Robust standard errors are in parentheses, adjusted for clustering by state. In Panel A, the dependent variable is the cumulative number of COVID-19 cases per 10,000. In Panel B, the dependent variable is the differential in vote for Trump in 2020 and 2016. We report the second stage estimates of our 2SLS (equation 2). In columns 1 and 2 we document the relationship between COVID-19 cases and the differential in vote for Trump in 2020 and 2016 for states that Trump and Clinton won, respectively. Columns 3 and 4 restrict the sample to swing and nonswing states. Columns 5 and 6 restrict the sample to urban and rural counties, respectively. The variables of interest are the cumulative number of COVID-19 cases per 10,000 (Panel A) and COVID-19 deaths per 100,000 (Panel B), respectively. Demographic controls include population, female population share, foreign-born population, non-Hispanic Black population, non-Hispanic White population and the share of the population by age groups. Socioeconomic controls include: share of the population with a college degree and four occupational indexes. Standard errors clustered by state in parentheses ${ }^{* * *} \mathrm{p}<0.01,{ }^{* *} \mathrm{p}<0.05,{ }^{*} \mathrm{p}<0.1$.

weaker than for cases, with F-statistics ranging from 2.88 in the less parsimonious model to 7.25 in our model with the full set of controls. The 2SLS estimates are all negative and of similar magnitude as our 2SLS estimates for cases, but more imprecise with only the estimate in columns 5 and 6 being statistically significant at a conventional level.

The fact that our 2SLS estimates are of the same magnitude for cases and deaths suggests that our results are robust to the use of deaths instead of cases. Nonetheless, two differences are worth mentioning. First, our instrumental variable is only weakly related to COVID-19 deaths. This is visible in Appendix Figure A7 with a very small differences in death per capita since mid-September 2020 for counties with and without employment in meat-processing factories. The probability that a 
COVID-19 infection results in death rises dramatically with age, and we expect that this and other factors such as healthcare coverage may contribute to the divergence in estimated effects. Second, it is plausible that voters are less aware or less likely to know someone who has died of COVID-19 than to know someone who has tested positive for COVID-19.

Voters' Mobilization One of the defining outcomes of the 2020 presidential election was the record-high turnout. Both presidential candidates would had won any previous elections, given their number of votes at the national level. We use differences in total votes between the 2016 and 2020 presidential elections as a rough proxy of turnout. We run the same model specification as in equations 1 and 2. We show the results in Table A8. We find no evidence that COVID-19 cases affected voters' mobilization.

Robustness Checks Appendix Table A4 provides robustness checks for our 2SLS results. In this table, we add to the models the well-known predictors of voting behavior or COVID-19 incidence. Column 1 reports our estimates for our favorite 2SLS specification (i.e., Table 2, column 5) as a benchmark. In column 2, following Autor et al. (2020), we add to the model the China shock variable, which contributes to explain President Trump's victory in $2016 .{ }^{28}$ Column 3 adds to the model precipitation and air pollution controls (i.e., PM2.5 and precipitation for the first months of the pandemic). ${ }^{29}$ In column 4 , we control for the share of employment in nursing care facilities. ${ }^{30}$ In column 5 , we control for the duration (in days) of the following statewide non-pharmaceutical interventions: stay-at-home orders, mandatory face mask policies, day care closures, freezes on evictions, and mandated quarantine for out-of-state individuals. Last, we include all these additional controls in column $6{ }^{31}$ Overall, the inclusion of one or all of these control variables has no effect on the magnitude and significance of our 2SLS estimates.

Appendix Tables A5 and A6 tackle another potential issue. We check whether our OLS and 2SLS point estimates vary if we change the date for the moment in

\footnotetext{
${ }^{28}$ The China shock variable is a Bartik measure capturing rising Chinese imports to the United States in each industry $i$, weighted by baseline share of workers in the same industry $i$ in each county. This variable varies both across counties and over time. The over-time variation is given by the difference in imports from China to the U.S. between 2000 (i.e., pre-accession to the WTO) to the period 2016-2019 (i.e., average value over this four-year window).

${ }^{29} \mathrm{~A}$ number of studies provide suggestive evidence that air pollution may be associated with an increased risk of COVID-19 death (Wu et al. (2020)).

${ }^{30}$ http://jedkolko.com/2020/10/18/the-geography-of-the-covid19-third-wave/ [consulted on November 2, 2020].

${ }^{31}$ Note that we only have data for statewide non-pharmaceutical interventions. One exception is for stay-at-home orders, which have been implemented by some cities and counties prior to statewide orders. Typically, the city or county order precedes the statewide order by few days.
} 
which we calculate the cumulative number of COVID-19 cases. As stated in our preanalysis plan, we rely on October 22nd for our main analysis. In these two appendix tables, we instead rely on July 1st (column 1), August 1st (column 2), September 1st (column 3), and August 1st (column 4). The estimates for the OLS are all larger and more significant than for our baseline, i.e., cases as of October 22nd, suggesting that we are very conservative in estimating the relationship between COVID-19 cases and the differential in votes for Trump. For the 2SLS, the point estimates all range from 0.0010 to 0.0012 and are statistically significant at the $5 \%$ level.

\section{Conclusion}

This paper explores the effect of the COVID-19 pandemic on the 2020 U.S. presidential election using both a reduced form and IV approach. Our key finding is that COVID-19 cases decreased electoral support for Trump. A simple counterfactual exercise shows that, ceteris paribus, if COVID-19 cases had been 5 percent lower, Trump would have retained the U.S. presidency for a second term. We find that the negative impact of COVID-19 incidence on President Trump's support is stronger (1) in states that Trump won in the 2016 presidential elections, (2) in swing states, and (3) in urban counties. We find no evidence that worsening economic conditions reduce electoral support for President Trump and that COVID-19 cases affect voters' mobilization.

At least two explanations are consistent with these findings. First, voters may have electorally sanctioned President Trump for how he handled the pandemic, which has been largely at odds with the approach of every other leader in developed countries, and is widely viewed to have contributed to the large numbers of infections and deaths in the US. This explanation is consistent with a retrospective voting approach (Fiorina 1981, Fearon 1999), in which voters sanction the incumbent for his handling of negative shocks.

Second, some voters may have switched from Trump to Biden due to changes in preferences triggered by the pandemic and the recession. In particular, a severe public health threat and major economic losses may have shifted preferences in favor of an expansion of the social safety net, including healthcare and unemployment insurance programs Rees-Jones et al. (2020b). Since the Democratic Party and its presidential candidate is more likely to champion these policies, it has reaped the electoral benefits of this switch in voters' preferences. This explanation is in line with studies claiming that political preferences are shaped by personal experience. If it is true that these changes in preferences are long lasting (Giuliano and Spilimbergo 2014), the Democratic Party also should be able to capitalize electorally in subsequent elections, especially in the areas hit the hardest by the pandemic. 
Our empirical analysis is unable to tease out which of these two channels is operative. Future research should investigate these mechanisms using individuallevel data, when they become available. Similarly, future studies should explore how turnout, which has been unprecedentedly high for the 2020 presidential election, has affected the results reported in this paper. 


\section{References}

Abney, F. G. and Hill, L. B.: 1966, Natural Disasters as a Political Variable: The Effect of a Hurricane on an Urban Election, American Political Science Review 60(4), 974-981.

Allcott, H., Boxell, L., Conway, J., Gentzkow, M., Thaler, M. and Yang, D. Y.: 2020, Polarization and Public Health: Partisan Differences in Social Distancing During the Coronavirus Pandemic, Journal of Public Economics 191, 104254.

Ashworth, S.: 2012, Electoral Accountability: Recent Theoretical and Empirical Work, Annual Review of Political Science 15(1), 183-201.

Autor, D., Dorn, D., Hanson, G. and Majlesi, K.: 2020, Importing Political Polarization? The Electoral Consequences of Rising Trade Exposure, American Economic Review 110(10), 3139-3183.

Baker, S. R., Farrokhnia, R. A., Meyer, S., Pagel, M. and Yannelis, C.: Forthcoming, How Does Household Spending Respond to an Epidemic? Consumption During the 2020 COVID-19 Pandemic, Review of Asset Pricing Studies .

Beland, L.-P., Brodeur, A. and Wright, T.: 2020, The Short-Term Economic Consequences of COVID-19: Exposure to Disease, Remote Work and Government Response. IZA Discussion Paper 13159.

Brodeur, A., Cook, N. and Heyes, A.: 2020, Methods Matter: P-Hacking and Publication Bias in Causal Analysis in Economics, American Economic Review 110(11).

Brodeur, A., Gray, D. M., Islam, A. and Bhuiyan, S.: 2020, A Literature Review of the Economics of COVID-19. IZA Discussion Paper 13411.

Canes-Wrone, Brandice, M. C. H. and Shotts, K. W.: 2001, Leadership and Pandering: A Theory of Executive Policymaking, American Journal of Political Science $\mathbf{4 5}(3), 532-550$.

Chen, J.: 2012, Distributive Spending, Voter Partisanship, and Political Participation: A Theory of Voter Turnout as Retrospective Evaluation, American Journal of Political Science 60(4), 974-981.

Chetty, R., Friedman, J. N., Hendren, N., Stepner, M. et al.: 2020, How Did COVID-19 and Stabilization Policies Affect Spending and Employment? A New Real-Time Economic Tracker Based on Private Sector Data. NBER Working Paper 27431.

Coibion, O., Gorodnichenko, Y. and Weber, M.: 2020, Labor Markets During the COVID-19 Crisis: A Preliminary View. NBER Working Paper 27017.

Dingel, J. I. and Neiman, B.: 2020, How Many Jobs Can be Done at Home?, Journal of Public Economics 189, 104235. 
Erikson, R. S. and Stoker, L.: 2001, Caught in the draft: The effects of vietnam draft lottery status on political attitudes, American Political Science Review 105(2), 221-237.

Fearon, J. D.: 1999, Electoral Accountability and the Control of Politicians: Selecting Good Types Versus Sanctioning Poor Performance, Democracy, accountability, and representation, Cambridge University Press, pp. 55-97.

Ferejohn, J.: 1986, Incumbent Performance and Electoral Control, Public Choice $\mathbf{5 0}(1-3), 5-25$.

Fiorina, M. P.: 1981, Retrospective voting in American national elections, Yale University Press.

Gerber, A. and Malhotra, N.: 2008, Do Statistical Reporting Standards Affect what Is Published? Publication Bias in Two Leading Political Science Journals, Quarterly Journal of Political Science 3(3), 313-326.

Giuliano, P. and Spilimbergo, A.: 2014, Growing Up in a Recession, Review of Economic Studies 81(2), 787-817.

Gollwitzer, A., Martel, C., Brady, W. J., Parnamets, P., Freedman, I. G., Knowles, E. D. and Van Bavel, J. J.: 2020, Partisan Differences in Physical Distancing Are Linked to Health Outcomes During the COVID-19 Pandemic, Nature Human Behaviour .

Healy, A. and Malhotra, N.: 2020, Retrospective Voting Reconsidered, Annual Review of Political Science 16, 285-306.

Kinder, D. R. and Kiewiet, D. R.: 1981, Sociotropic politics: The american case, British Journal of Political Science 11(2), 129-161.

Lau, Richard R., T. A. B. and Sears, D. O.: 1978, Self-interest and civilians' attitudes toward the vietnam war, Public Opinion Quarterly 42(4), 464-482.

Lenz, G. and Sahn, A.: Forthcoming, Achieving Statistical Significance with Control Variables and without Transparency, Political Analysis .

Malhotra, N. and Kuo, A. G.: 2008, Attributing Blame: The Public's Response to Hurricane Katrina, Journal of Politics 70(1), 120-135.

Margalit, Y. M.: 2013, Explaining Social Policy Preferences: Evidence from the Great Recession, American Political Science Review 107(1), 80-103.

Mo, C. H. and Conn, K.: 2018, When do the advantaged see the disadvantages of others? a quasi-experimental study of national service, American Political Science Review 112(4), 721-741.

Persson, Torsten, G. R. and Tabellini, G.: 1997, Separation of Powers and Political Accountability, Quarterly Journal of Economics 112(4), 1163-1202.

Raifman, J., Nocka, K., Jones, D., Bor, J., Lipson, S., Jay, J., Cole, M., Krawczyk, N., Chan, P., Galea, S. et al.: 2020, COVID-19 US State Policy Database. MI: Inter-university Consortium for Political and Social Research. 
Rees-Jones, A., D’Attoma, J., Piolatto, A. and Salvadori, L.: 2020a, COVID-19 Changed Tastes for Safety-Net Programs. NBER Working Paper 27865.

Rees-Jones, A., D'Attoma, J., Piolatto, A. and Salvadori, L.: 2020b, Covid-19 changed tastes for safety-net programs, Technical report, National Bureau of Economic Research.

Wu, X., Nethery, R. C., Sabath, B. M., Braun, D. and Dominici, F.: 2020, Exposure to Air Pollution and COVID-19 Mortality in the United States. medRxiv. 


\section{Appendix: NOT FOR PUBLICATION}

\section{Deviations from Pre-Analysis Plan}

For the empirical analysis, we follow the specifications and test the hypotheses detailed in our pre-analysis plan (PAP). Our PAP was archived on October 30th, 2020, at https://osf.io/xvuzp/, four days prior to the Presidential Elections. We relied on a PAP to minimize issues of specification searching and p-hacking. A growing literature documents the extent of p-hacking in the social sciences, highlighting that the extent of p-hacking is larger for observational studies than for experimental studies (e.g., Brodeur, Cook and Heyes (2020); Gerber and Malhotra (2008); Lenz and Sahn (Forthcoming)). Another advantage of relying on a PAP is that it allowed us to think carefully about the analyses to be conducted prior to the outcome of the Presidential Elections. This is potentially important given the growing concerns that social science researchers may be politically biased.

We aimed to follow the PAP to the greatest extent possible, but made some modifications following suggestions from other researchers and gaining access to the voting data. We try to be as transparent as possible and list in what follows all the modifications made to the pre-analysis plan and supplementary analyses not included in the PAP.

\section{Modifications to the PAP:}

While we follow the PAP for the choice of control variables for our main specifications, we added control variables as a robustness check in Appendix Table A4. The additional control variables are only included in this table and have no effect on the conclusions of this paper.

Another modification that was made to the PAP was to exclude the analysis on the impacts of non-pharmaceutical interventions. We instead include these statewide policy variables as controls in Appendix Table A4. Our decision to not conduct this analysis is based on the fact that our model includes state fixed effects and that we have access to county-level policy changes only for stay-at-home orders. Furthermore, stay-at-home orders implemented by cities or counties typically preceded statewide orders by only a few days. There is thus not enough variation to conduct this analysis with state fixed effects.

We also added one outcome variable to the analysis: differences in total votes between the 2016 and 2020 presidential elections. We rely on the same (OLS and 2SLS) specifications and control variables as for the analyzes for the differential voting share for Trump from 2016 to 2020. We added this variable because of the record-high turnout. 
The last modification we have made to the PAP is to change the list of states considered "Swing". In this paper, we classify states as swing or non-swing states using the NYT classification available at https://www.nytimes.com/interactive/ 2020/us/elections/electoral-college-battleground-states.html, while we write in the PAP that "We classify states as swing or non-swing states using election polls compiled by Dave Leip's Atlas of U.S. Presidential Elections. We rely on the latest three polls as of October 25th, 2020 and consider swing states as states in which the spread is 5 or less: Arizona, North Carolina, Florida, Georgia, Iowa, Ohio, Texas and Alaska. We also add the following three states which have been labeled as swing states in the media and included in Dave Leip's report on closest states: Michigan, Wisconsin and Pennsylvania."

In practice, we add the following states as swing states in the paper: Minnesota, Nevada, New Hampshire, Maine and Nebraska. We show in Appendix Table A7 that using the states stated in the PAP leads to similar conclusions.

\section{Occupational Measures}

The exposure to disease or infection and physical proximity indexes were developed using the Occupational Information Network $\left(\mathrm{O}^{*} \mathrm{NET}\right)$ survey data. O*NET is an online database that gathers occupational data and develops applications to help the workforce better understand the U.S. labor market. More precisely, the index of exposure to disease is taken from a survey question asking, "How often does this job require exposure to disease/infections?" The physical proximity index is built using answers to the question "How often does this job require exposure to disease/infections?" The answers to these two questions include five possible answers: (1) Never, (2) Once a year or more but not every month, (3) Once a month or more but not every week, (4) Once a week or more but not every day, and (5) Every day. Occupations such as dental hygienist score 100 (the maximum) in both indexes. Our third index captures the likelihood that a worker in a given occupation is designated an essential worker. Essential worker designations are based on the LMI Institute index. ${ }^{32}$ Our last index is measuring feasibility of remote work at the occupation level. Using this index, Dingel and Neiman (2020) argue that $34 \%$ of U.S. jobs can plausibly be performed at home. The indexes were built using data collected prior to the pandemic. It is thus plausible that they are changing over time in response to the pandemic.

\footnotetext{
${ }^{32}$ See https://www.Imiontheweb.org/ for more details [consulted on October 25, 2020].
} 


\section{Non-Pharmaceutical Interventions}

We also gather data on the following COVID-19 policies: stay-at-home order, mandatory face mask policies, day care closures, freezes on eviction, and mandated quarantine for individuals arriving from another state. Data on policy duration are drawn from Raifman et al. (2020).

Stay-at-home order: "The date a state's stay at home/shelter in place order went into effect. Only included directives/orders. Did not include guidance or recommendations. Order must apply to entire state."

Day care closure: "The date a state closed daycares statewide. Only included directives/orders. Did not include guidance or recommendations. Order must apply to entire state."

Face masks: "The date a state mandated face mask use in public spaces by all individuals statewide. The order does not have to apply to all public spaces, but must apply state wide. Only included directives/orders. Did not include guidance or recommendations. Order must apply to entire state."

Freezes on evictions: "The date a state stopped the initiation of evictions (overall or due to COVID-19 related issues) statewide. This could be mandated from governors or though the state court system. Did not include guidance or recommendations. Order must apply to entire state."

Quarantine: "The date a state first mandated that individuals arriving in their state from any state must undergo quarantine. Did not include guidance or recommendations. Order must apply to entire state. Quarantine order must apply to visitors using all forms of transportation to enter the state (not just air travel)." 
Figure A1: Cumulative Number of COVID-19 Deaths per 100,000

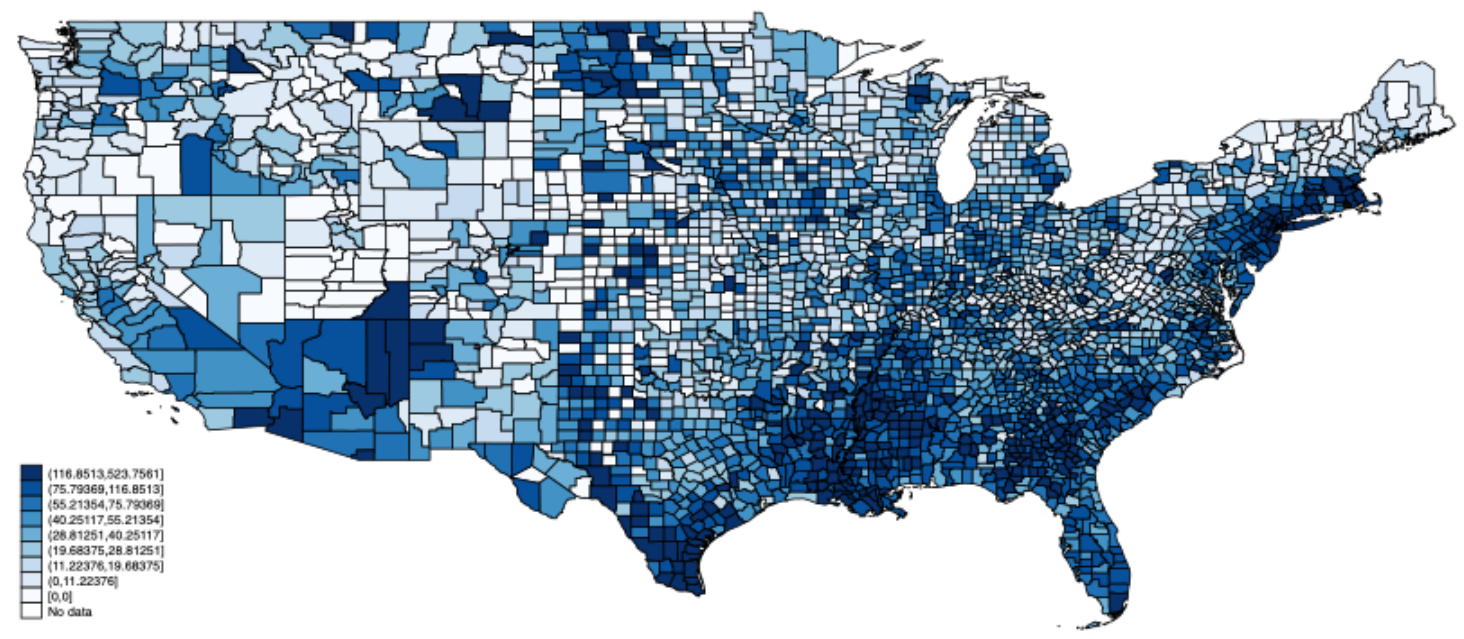

Notes: This figure illustrates the the cumulative number of COVID-19 deaths per 100,000 as of October22, 2020.

Figure A2: Share of Votes for the Republican Party in 2020

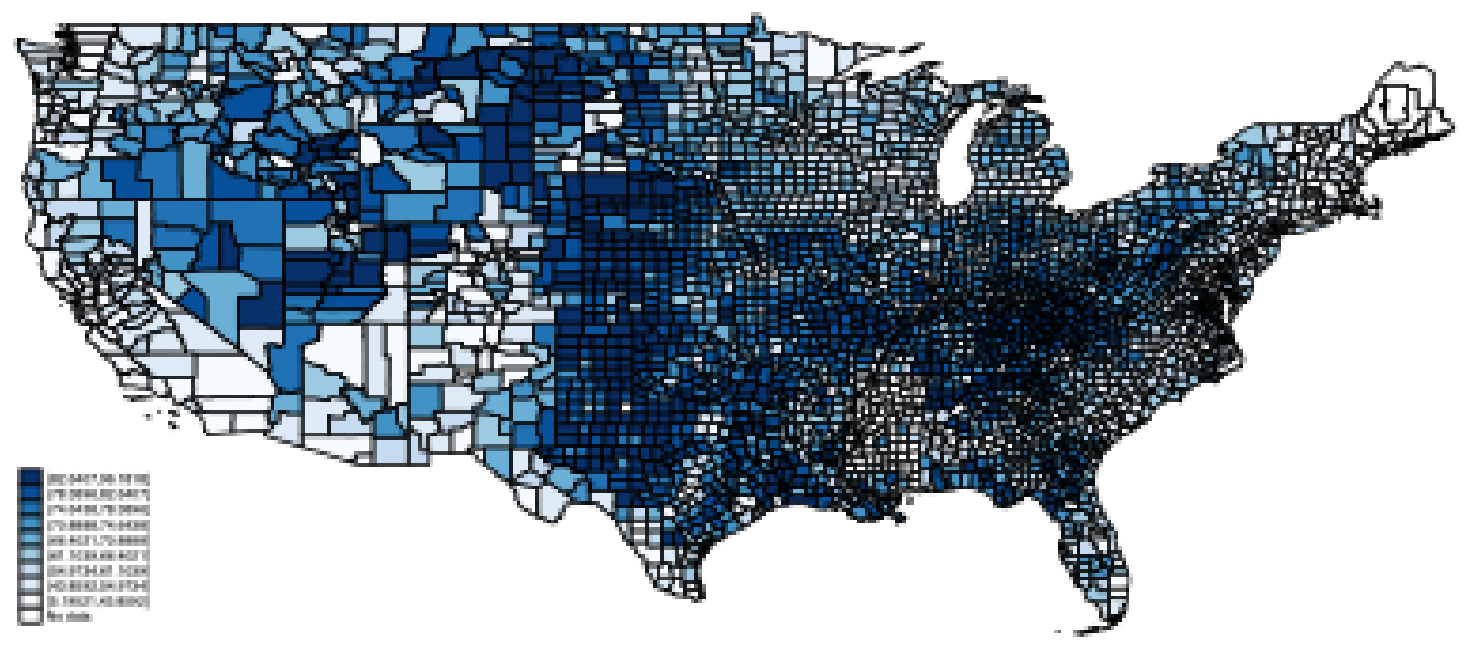

Notes: This figure illustrates the share of votes for the Republican Party during the 2020 Presidential Elections. 
Figure A3: Share of Votes for the Republican Party in 2016

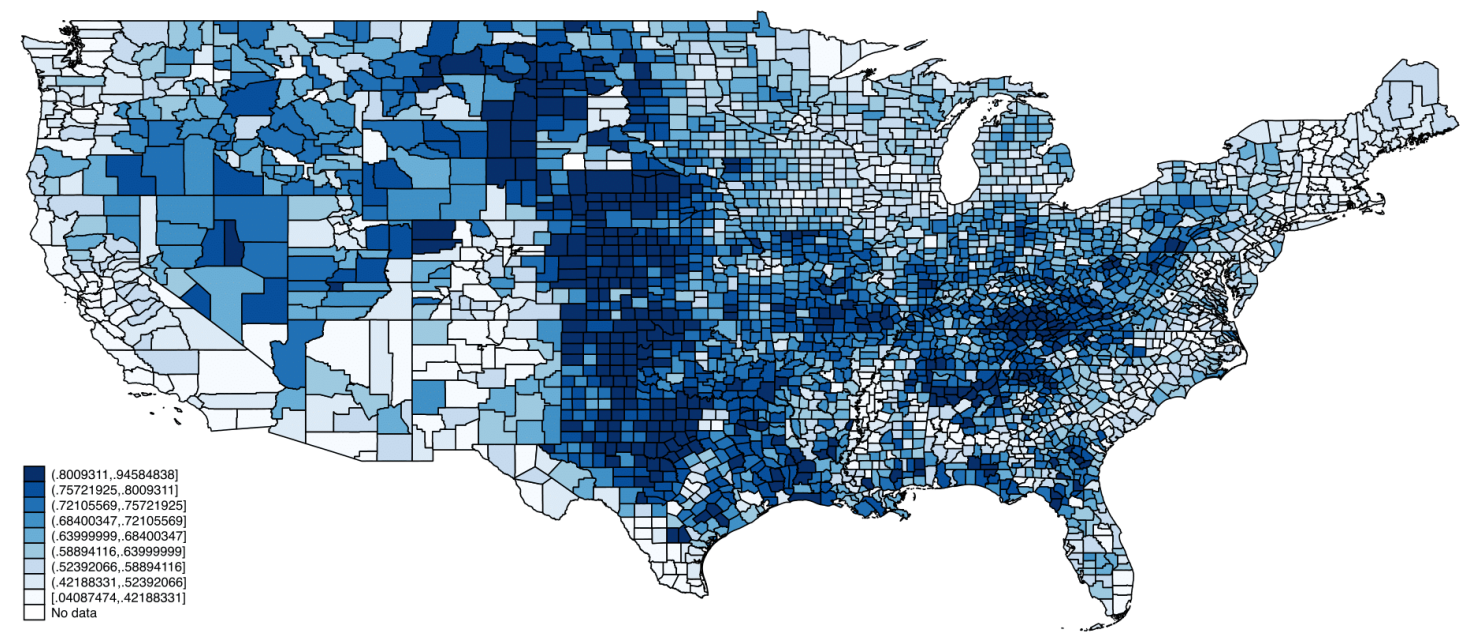

Notes: This figure illustrates the share of votes for the Republican Party during the 2016 Presidential Elections.

Figure A4: Change in Unemployment from before to During COVID-19

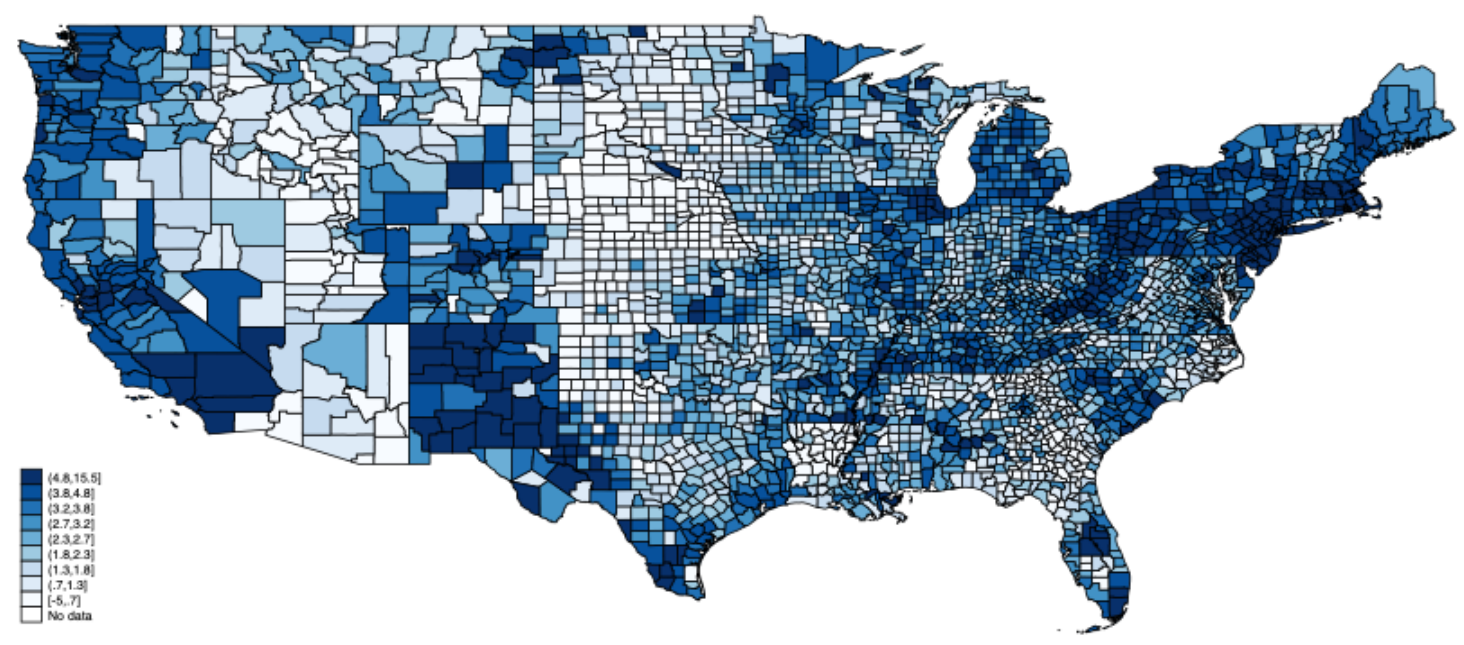

Notes: This figure illustrates the change in the unemployment rate from August 2019 to August 2020. Data from the U.S. Bureau of Labor Statistics' Local Area Unemployment Statistics. 
Figure A5: Share of Employment in Processing Meat Factories

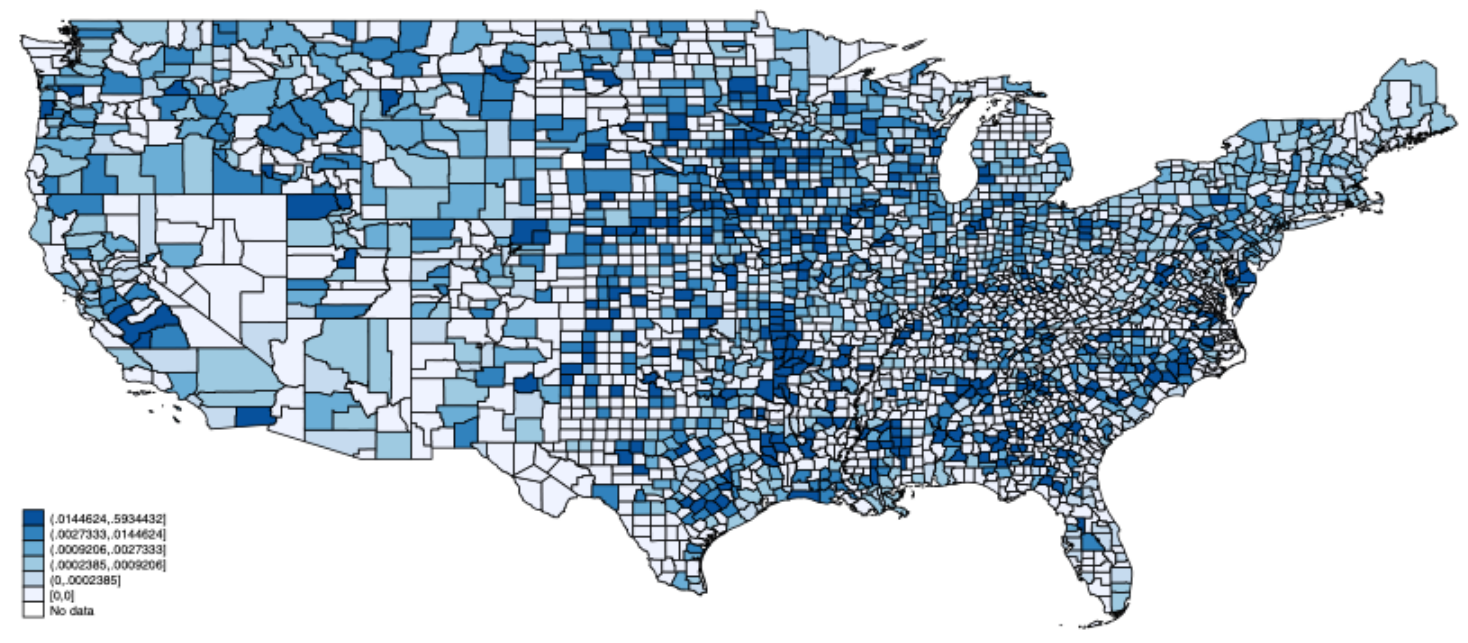

Notes: This figure illustrates the share of employment in processing meat factories. Data is from the County Business Patterns.

Figure A6: COVID-19 Cases and the Share of Employment in Processing Meat Factories

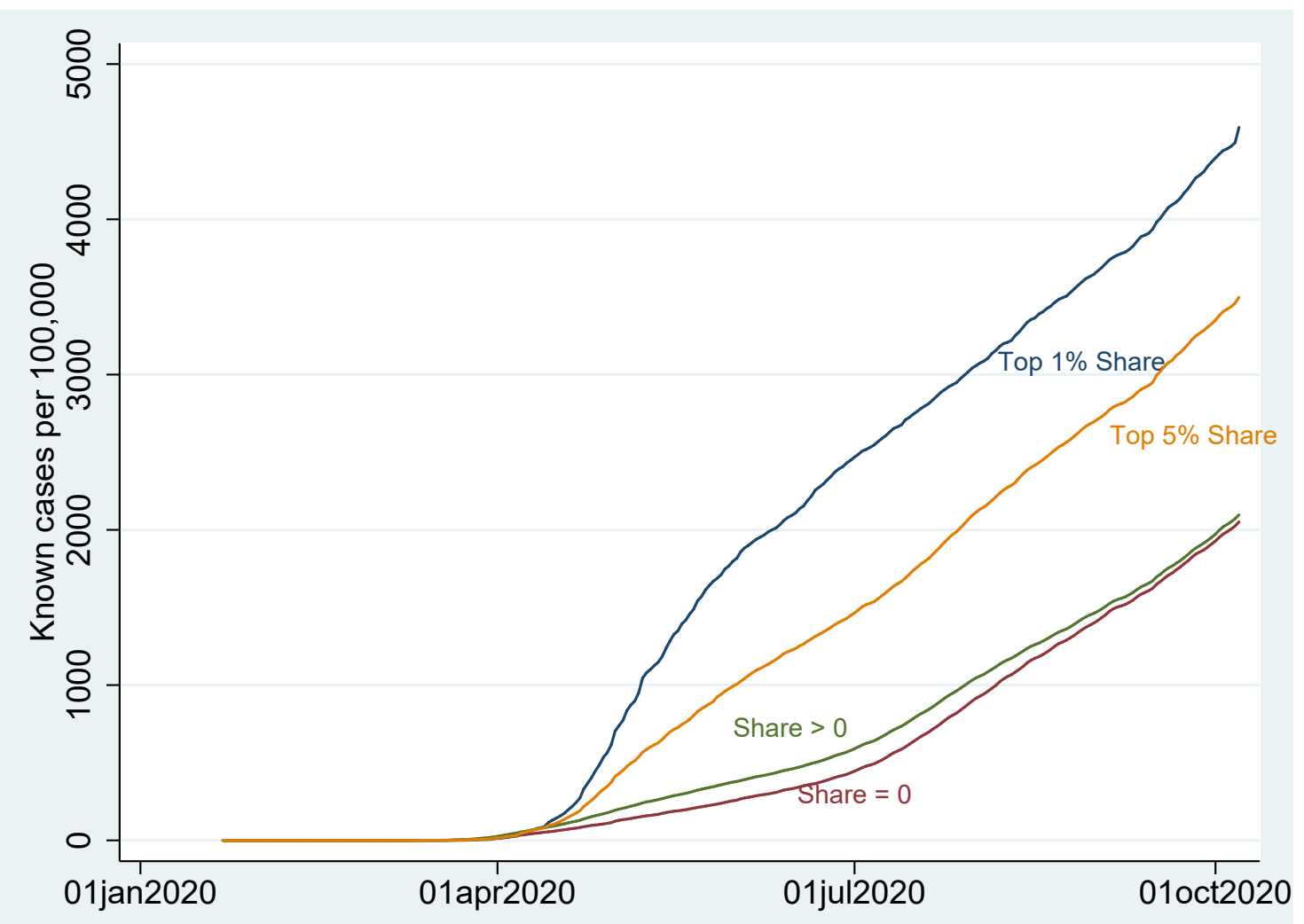

Notes: This figure illustrates the cumulative number of number of COVID-19 cases and the share of employment in processing meat factories for the (1) top $1 \%$ of counties with highest share of employment in processing meat factories, (2) top $5 \%$ of counties with highest share of employment in processing meat factories, (3) counties with at least one job in processing meat factories, and (4) counties without any jobs in processing meat factories. Employment data is from the County Business Patterns. 
Figure A7: COVID-19 Deaths and the Share of Employment in Processing Meat Factories

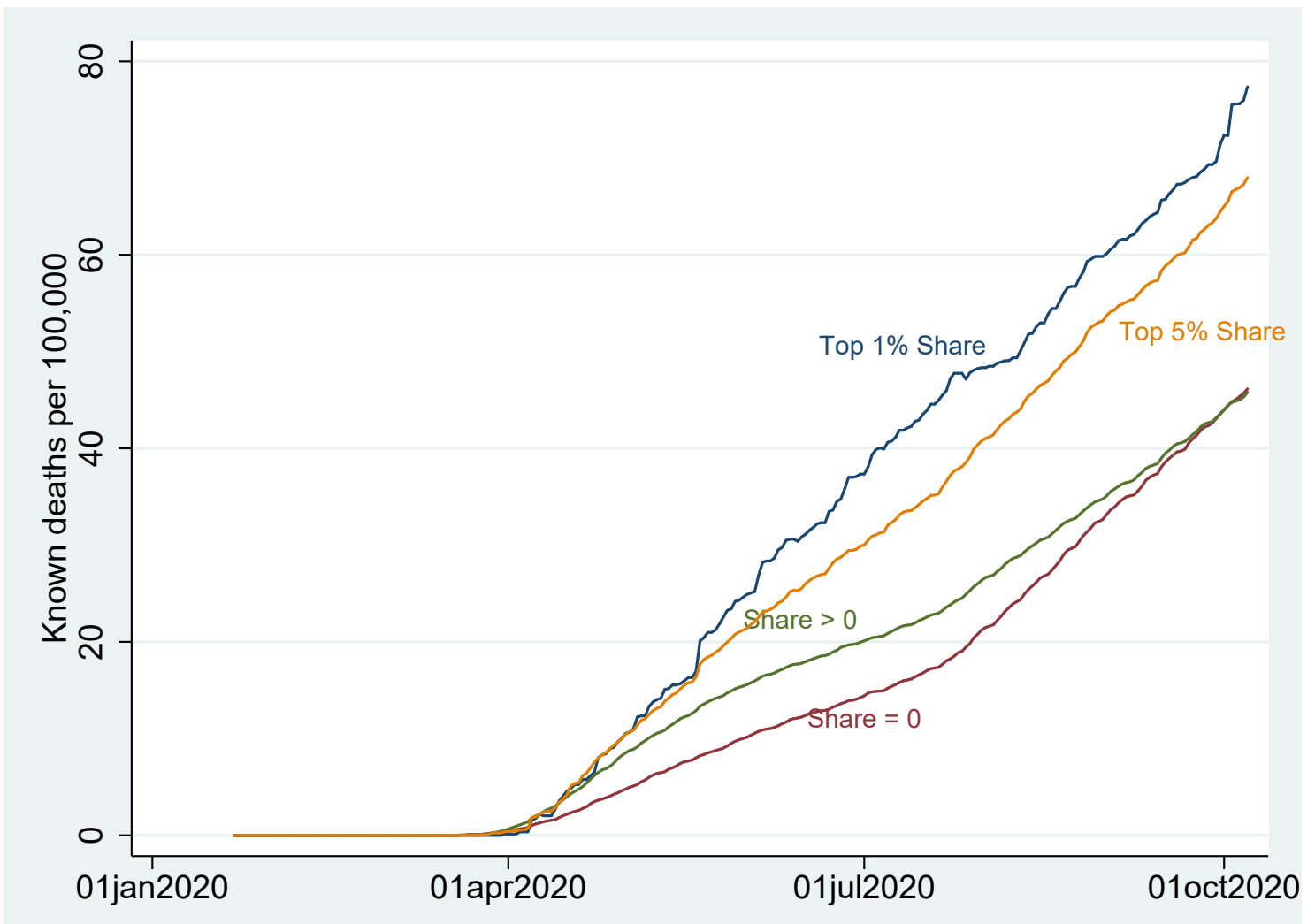

Notes: This figure illustrates the cumulative number of number of COVID-19 deaths and the share of employment in processing meat factories for the (1) top $1 \%$ of counties with highest share of employment in processing meat factories, (2) top $5 \%$ of counties with highest share of employment in processing meat factories, (3) counties with at least one job in processing meat factories, and (4) counties without any jobs in processing meat factories. Employment data is from the County Business Patterns.

Figure A8: Changes in Total Votes from 2016 to 2020

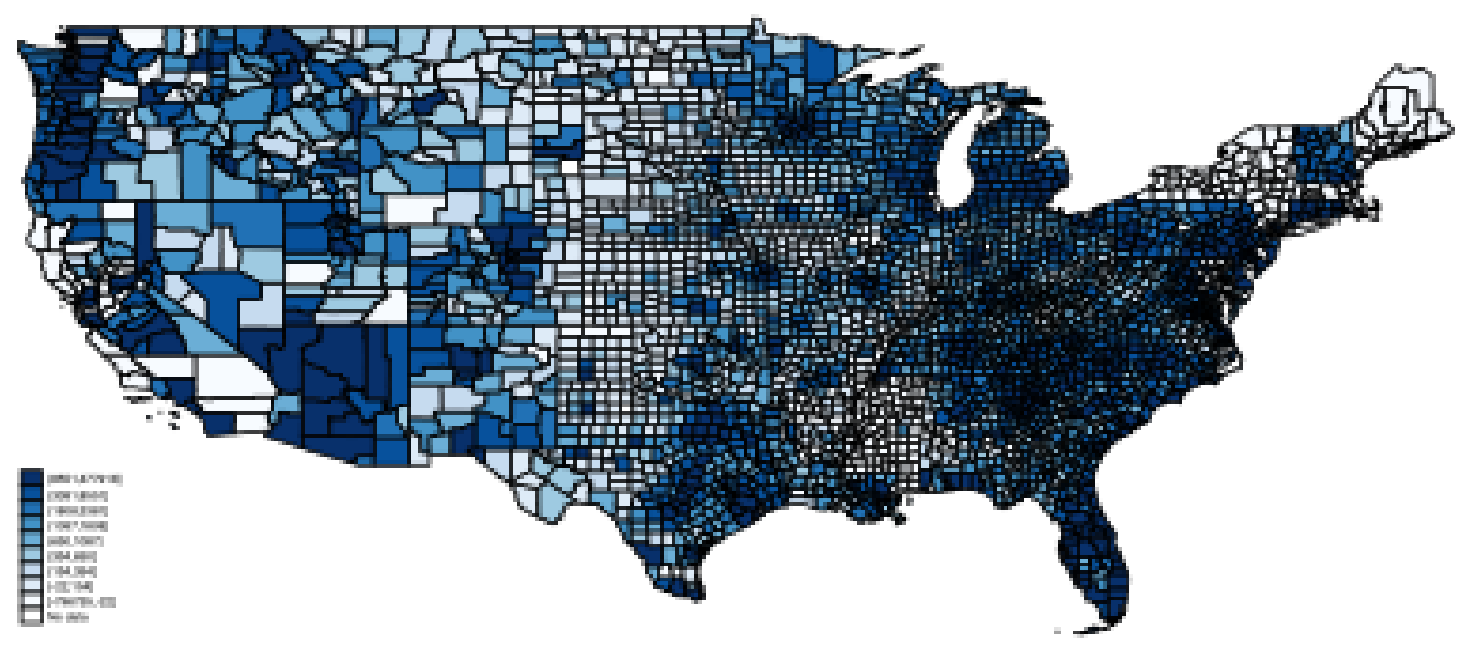

Notes: This figure illustrates changes in total votes from the 2016 to 2020 Presidential Elections. 
Impact of COVID-19 Cases

(1)

(2)

(3)
Impact of COVID-19 Deaths

(4)

(5)

(6)

\section{Panel A}

Trump Vote

$0.0078^{* * *}$

$0.0078^{* * *}$

$0.0057^{* *}$

0.0056

0.0052

$0.0081^{* *}$

Share 2020

$(0.0021)$

$(0.0022)$

$(0.0022)$

$(0.0042)$

$(0.0040)$

$(0.0040)$

\section{Panel B}

Trump Vote

$0.0088^{* * *}$

$0.0087^{* * *}$

$0.0068 * * *$

0.0038

0.0034

0.0062

Share 2016

$(0.0025)$

(0.0025)

$(0.0025)$

(0.0049)

$(0.0045)$

(0.0043)

\section{Panel C}

Change Trump Vote

$-0.0013$

$-0.0013$

$-0.0013$

0.0012

0.0012

0.0011

from 2012 to 2016

(0.0009)

(0.0009)

(0.0009)

(0.0012)

(0.0012)

(0.0012)

\section{State FE}

Demographic Controls

Socioeconomic Controls

$\begin{array}{cc}\text { Yes } & \text { Yes } \\ \text { Yes } & \text { Yes } \\ & \text { Yes }\end{array}$

Social Distancing

Observations

2,627

2,627

Yes
Yes
Yes
Yes
2,627

Yes

Yes

Yes

Yes

Yes

Yes

Yes

Notes: Election data from Dave Leip's Atlas of US Presidential Elections. An observation is a county. Each point estimate is from a different regression. Robust standard errors are in parentheses, adjusted for clustering by state. In Panel A, the dependent variable is the vote share for the Republican Party in 2020. In Panel B, the dependent variable is the vote share for Trump in 2016. In the Panel c, the dependent variable is the differential in vote for Trump in 2016 and 2012. The variables of interest are the cumulative number of COVID-19 cases per 10,000 (columns 1-3) and COVID19 deaths per 100,000 (columns 4-6). Demographic controls include population, female population share, foreign-born population, Non-Hispanic Black population, Non-Hispanic White population and the share of the population by age groups. Socioeconomic controls include: share of the population with a college degree and four occupational indexes. Standard errors clustered by state in parentheses ${ }^{* * *} \mathrm{p}<0.01,{ }^{* *} \mathrm{p}<0.05,{ }^{*} \mathrm{p}<0.1$. 
Table A2: The Impacts of COVID-19 Cases (2SLS): Heterogeneity Analyses by Demographic Characteristics

\begin{tabular}{|c|c|c|c|c|c|c|}
\hline Panel A: First Stage & $(1)$ & \multicolumn{5}{|c|}{ Cumulative COVID Cases } \\
\hline $\begin{array}{l}\text { Share Workers Meat } \\
\text { Processing Plants }\end{array}$ & $\begin{array}{c}325.74^{* * *} \\
(111.42)\end{array}$ & $\begin{array}{c}280.34^{* * *} \\
(105.96)\end{array}$ & $\begin{array}{c}331.19^{* * *} \\
(97.50)\end{array}$ & $\begin{array}{c}28.40 \\
(75.94)\end{array}$ & $\begin{array}{c}338.04^{* * *} \\
(104.85)\end{array}$ & $\begin{array}{l}226.38^{* * *} \\
(73.05)\end{array}$ \\
\hline \multicolumn{7}{|l|}{ Panel B: 2SLS } \\
\hline & \multicolumn{6}{|c|}{$\begin{array}{l}\text { Change in Republican Vote } \\
\text { from } 2016 \text { to } 2020\end{array}$} \\
\hline & Below & Above & Below & Above & Below & Above \\
\hline & Median & Median & Median & Median & Median & Median \\
\hline & 65 Years & 65 Years & White & White & College & College \\
\hline & (1) & (2) & $\begin{array}{l}\text { non-Hisp. } \\
(3)\end{array}$ & $\begin{array}{l}\text { non-Hisp. } \\
(4)\end{array}$ & (5) & (6) \\
\hline Cumulative COVID & $-0.0154^{* * *}$ & -0.0047 & $-0.0123^{* * *}$ & -0.0358 & $-0.0135 * * *$ & 0.00182 \\
\hline Cases per 10,000 & $(0.0057)$ & $(0.0037)$ & $(0.0041)$ & $(0.1130)$ & $(0.0038)$ & $(0.0055)$ \\
\hline State FE & Yes & Yes & Yes & Yes & Yes & Yes \\
\hline Share Manufacturing Emp. & Yes & Yes & Yes & Yes & Yes & Yes \\
\hline Demographic Controls & Yes & Yes & Yes & Yes & Yes & Yes \\
\hline Socioeconomic Controls & Yes & Yes & Yes & Yes & Yes & Yes \\
\hline Social Distancing & Yes & Yes & Yes & Yes & Yes & Yes \\
\hline Observations & 1,399 & 1,187 & 1,312 & 1,274 & 1,333 & 1,253 \\
\hline F-Statistics & 23.29 & 24.68 & 29.20 & 0.14 & 33.97 & 9.12 \\
\hline
\end{tabular}

Notes: Election data from Dave Leip's Atlas of US Presidential Elections. An observation is a county. Robust standard errors are in parentheses, adjusted for clustering by state. In Panel A, the dependent variable is the cumulative number of COVID-19 cases per 10,000. In Panel B, the dependent variable is the differential in vote for the Republican Party in 2020 and 2016. We report the second stage estimates of our 2SLS (equation 2). We restrict the sample to counties: below (column 1) and above (column 2) the median percentage of residents aged 65; below (column 3) and above (column 4) the median percentage of white (non Hispanic) residents; and below (column 5) and above (column 6) the median percentage of residents who attended college. The variable of interest is the cumulative number of COVID-19 cases per 10,000. Demographic controls include population, female population share, foreign-born population, Non-Hispanic Black population, Non-Hispanic White population and the share of the population by age groups. Socioeconomic controls include: share of the population with a college degree and four occupational indexes. Standard errors clustered by state in parentheses ${ }^{* * *} \mathrm{p}<0.01,{ }^{* *} \mathrm{p}<0.05,{ }^{*} \mathrm{p}<0.1$. 
Table A3: The Impacts of COVID-19 Deaths: OLS and 2SLS Estimates

Panel A: First Stage

(1)

(2)

(3)

Cumulative COVID Deaths

(4)

(5)

(6)

Share Workers Meat

29.19

$44.27^{*}$

(23.54)

(24.08)

$47.13^{* *}$

Processing Plants

(23.54)

(22.29)

Panel B: OLS and 2SLS

Change in Trump Vote

from 2016 to 2020

(1)

(2)

(3)

(4)

(5)

(6)

Cumulative COVID
Deaths per 10,000

0.0009

0.0008

0.0008

$-0.1370$

$-0.0887^{*}$

$-0.0833^{*}$

(0.0016)

(0.0016)

$(0.0015)$

(0.1160)

(0.0534)

$(0.0454)$

Unemployment Change

0.0140

0.0846

(0.0882)

$(0.1210)$

State FE

Share Manufacturing Emp.

Yes

Yes

Yes

Yes

Yes

Yes

Demographic Controls

Yes

Yes

Yes

Yes

Socioeconomic Controls

Social Distancing

Observations

Yes

Yes

Yes

Yes

Yes

Yes

Cragg-Donald F-Statistics

2,586

Yes

Yes

Yes

Yes

Yes

Yes

Yes

Yes

2,586

2,586

2,586

2,586

2,586

2.88

6.49

7.25

Notes: Election data from Dave Leip's Atlas of US Presidential Elections. An observation is a county. Robust standard errors are in parentheses, adjusted for clustering by state. We present OLS estimates in columns 1-3 of specification 1. We present the first stage (Panel A) and the 2-stage estimates (Panel B) of specification (2) in columns 4-6 in which we instrument COVID-19 incidence in a first stage by the share of employment in processing meat factories. In Panel A, the dependent variable is the cumulative number of COVID-19 cases per 10,000 (columns 4-6). In Panel B, the dependent variable is the differential in vote for Trump in 2020 and 2016. Demographic controls include population, female population share, foreign-born population, Non-Hispanic Black population, Non-Hispanic White population and the share of the population by age groups. Socioeconomic controls include: share of the population with a college degree and four occupational indexes. The Unemployment change variable is the unemployment rate as of September 2020 minus the unemployment rate as of September 2019. Standard errors clustered by state in parentheses $* * * \mathrm{p}<0.01, * * \mathrm{p}<0.05$, * $\mathrm{p}<0.1$. 
Table A4: 2SLS Estimates: Robustness Checks

\begin{tabular}{|c|c|c|c|c|c|c|}
\hline Panel A: First Stage & \multicolumn{6}{|c|}{ Cumulative COVID Cases } \\
\hline $\begin{array}{l}\text { Share Workers Meat } \\
\text { Processing Plants }\end{array}$ & $\begin{array}{c}327.06^{* * *} \\
(84.82)\end{array}$ & $\begin{array}{c}320.99^{* * * *} \\
(83.10)\end{array}$ & $\begin{array}{c}326.80^{* * * *} \\
(83.55)\end{array}$ & $\begin{array}{c}326.85^{* * *} \\
(84.50)\end{array}$ & $\begin{array}{c}326.40^{* * * *} \\
(84.30)\end{array}$ & $\begin{array}{c}320.82^{* * *} \\
(81.92)\end{array}$ \\
\hline
\end{tabular}

Panel B: 2SLS

(1)

Cumulative COVID

Cumulative COV
Cases per 10,000

\section{State FE}

Share Manufacturing Emp.

Demographic Controls

Socioeconomic Controls

Social Distancing

China Shock

Pollution \& Precip.

Statewide Interventions

Observations

Cragg-Donald F-Statistics
Share Nursing Employment

Change in Trump Vote

from 2016 to 2020

(2)

(3)

(4)

(5)

(6)

$\begin{array}{cccccc}-0.0120^{* * *} & -0.0109^{* * *} & -0.0119^{* * *} & -0.0120 * * * & -0.0120^{* * *} & -0.0108^{* * *} \\ (0.0004) & (0.0004) & (0.0004) & (0.0004) & (0.0004) & (0.0004)\end{array}$

Notes: Election data from Dave Leip's Atlas of US Presidential Elections. An observation is a county. Robust standard errors are in parentheses, adjusted for clustering by state. We present the first stage (Panel A) and the 2-stage estimates (Panel B) of specification (2) in which we instrument COVID-19 incidence in a first stage by the share of employment in processing meat factories. In Panel A, the dependent variable is the cumulative number of COVID-19 cases per 10,000. In Panel B, the dependent variable is the differential in vote for Trump in 2020 and 2016. Demographic controls include population, female population share, foreign-born population, Non-Hispanic Black population, Non-Hispanic White population and the share of the population by age groups. Socioeconomic controls include: share of the population with a college degree and four occupational indexes. In column 2, we add to the model the China shock variable. Column 3 adds to the model precipitation and air pollution controls. In column 4, we control for the share of employment in nursing care facilities. Column 5, we control for the duration (in days) of the following statewide non-pharmaceutical interventions: stay-at-home order, mandatory face mask policies, day care closures, freezes on eviction, and mandated quarantine for out of state individuals. Standard errors clustered by state in parentheses $* * * \mathrm{p}<0.01, * * \mathrm{p}<0.05,{ }^{*} \mathrm{p}<0.1$. 
Table A5: OLS Estimates: Date for Cumulative COVID-19 Cases

\section{Change in Trump Vote}

from 2016 to 2020

(1)

(2)

(3)

(4)

$(5)$

$\begin{array}{ll}\text { Cumulative COVID Cases } & -0.0037^{*} \\ \text { per 10,000 July 1st } & (0.0021)\end{array}$

Cumulative COVID Cases

$-0.0032^{* *}$

per 10,000 August 1st

$(0.0015)$

Cumulative COVID Cases

$-0.0021^{* *}$

per 10,000 September 1st

(0.0009)

Cumulative COVID Cases

$-0.0016^{* *}$

per 10,000 October 1st

$(0.0008)$

Cumulative COVID Cases

$-0.0013^{*}$

per 10,000 October 22nd

$(0.0007)$

State FE

Share Manufacturing Emp.

Yes

Yes Yes

Yes Yes

Yes

Demographic Controls

Yes

Yes

Yes

Yes

Socioeconomic Controls

Yes

Yes

Yes

Yes

Yes

Social Distancing

Yes

Yes

Yes

Yes

Observations

2,586

Yes

Yes

Yes

Yes

Yes

Notes: Election data from Dave Leip's Atlas of US Presidential Elections. An observation is a county. Robust standard errors are in parentheses, adjusted for clustering by state. We present OLS estimates of specification (1). The dependent variable is the differential in vote for Trump in 2020 and 2016. The main independent variable is the cumulative number of COVID-19 cases per 10,000. We rely on different dates to calculate the cumulative number of cases. For instance, column 1 reports the estimates for the cumulative number of cases as of July 1st. In Panel B, Demographic controls include population, female population share, foreign-born population, Non-Hispanic Black population, Non-Hispanic White population and the share of the population by age groups. Socioeconomic controls include: share of the population with a college degree and four occupational indexes. Standard errors clustered by state in parentheses $* * * \mathrm{p}<0.01$, $\mathrm{p}<0.05,{ }^{*} \mathrm{p}<0.1$. 
Table A6: 2SLS Estimates: Date for Cumulative COVID-19 Cases

Panel A: First Stage

Cumulative COVID Cases

July 1

Aug. 1

Sept. 1

Oct. 1

Oct. 22

(1)

(2)

(3)

(4)

(5)

Share Workers Meat

$377.53^{* * *}$

$364.70^{* * *}$

$347.33^{* * *}$

$335.89^{* * *}$

$327.06^{* * *}$

Processing Plants

(71.67)

(69.80)

(71.46)

(78.30)

(84.82)

Panel B: 2SLS

Change in Trump Vote

from 2016 to 2020

(1)

(2)

(3)

(4)

(5)

Cumulative COVID

$-0.0104^{* * *}$

$-0.0108 * * *$

$-0.0113^{* * *}$

$-0.0117^{* * *}$

$-0.0120 * * *$

Cases per 10,000

(0.0038)

(0.0038)

(0.0041)

(0.0042)

$(0.0043)$

State FE

Share Manufacturing Emp.

\section{Yes}

Demographic Controls

Socioeconomic Controls

Social Distancing

Observations

Cragg-Donald F-Statistics
Yes

Yes

Yes

Yes

2,586

227.37

Yes
Yes
Yes
Yes
Yes
2,586
163.52

Yes
Yes
Yes
Yes
Yes
2,586
98.36

Yes

Yes

Yes

Yes

Yes

2,586

69.86
Yes

Yes

Yes

Yes

Yes

2,586

55.03

Notes: Election data from Dave Leip's Atlas of US Presidential Elections. An observation is a county. Robust standard errors are in parentheses, adjusted for clustering by state. We present the first stage (Panel A) and the 2-stage estimates (Panel B) of specification (2) in which we instrument COVID-19 incidence in a first stage by the share of employment in processing meat factories. In Panel A, the dependent variable is the cumulative number of COVID-19 cases per 10,000. We rely on different dates to calculate the cumulative number of cases. For instance, column 1 reports the estimates for the cumulative number of cases as of July 1st. In Panel B, the dependent variable is the differential in vote for Trump in 2020 and 2016. Demographic controls include population, female population share, foreign-born population, Non-Hispanic Black population, Non-Hispanic White population and the share of the population by age groups. Socioeconomic controls include: share of the population with a college degree and four occupational indexes. Standard errors clustered by state in parentheses $* * * \mathrm{p}<0.01, * * \mathrm{p}<0.05, * \mathrm{p}<0.1$. 
Table A7: The Impacts of COVID-19 Cases (2SLS) for Swing States: PAP vs Paper

Panel A: First Stage

Cumulative COVID Cases

(1)

(2)

(3)

(4)

$\begin{array}{lcccc}\text { Share Workers Meat } & 296.86^{* *} & 330.99^{* * *} & 426.39^{* * *} & 249.07^{* * *} \\ \text { Processing Plants } & (142.51) & (100.30) & (139.42) & (85.92)\end{array}$

Panel B: 2SLS

\section{Change in Trump Vote}

from 2016 to 2020

$\begin{array}{cccc}\text { Swing } & \text { Non Swing } & \text { Swing } & \text { Not Swing } \\ \text { States } & \text { States } & \text { States } & \text { States } \\ \text { PAP } & \text { PAP } & \text { Not PAP } & \text { Not PAP }\end{array}$

(1)

(2)

$(3)$

(4)

Cumulative COVID

$-0.0205^{* * *}$

$-0.0059^{*}$

$-0.0143^{* * *}$

$-0.0087^{* *}$

Cases per 10,000

(0.0041)

(0.0032)

(0.0042)

$(0.0044)$

State FE

Share Manufacturing Emp.

$\begin{array}{cc}\text { Yes } & \text { Yes } \\ \text { Yes } & \text { Yes } \\ \text { Yes } & \text { Yes } \\ \text { Yes } & \text { Yes } \\ \text { Yes } & \text { Yes } \\ 908 & 1,678 \\ 15.81 & 36.73\end{array}$

Yes

Yes

Demographic Controls

Socioeconomic Controls

Social Distancing

Observations

15.81

36.73

Yes

Yes

Yes Yes

Yes Yes

Yes Yes

F-Statistics

1,063

1,523

40.06

18.16

Notes: Election data from Dave Leip's Atlas of US Presidential Elections. An observation is a county. Robust standard errors are in parentheses, adjusted for clustering by state. In Panel A, the dependent variable is the cumulative number of COVID-19 cases per 10,000. In Panel B, the dependent variable is the differential in vote for Trump in 2020 and 2016 . We report the second stage estimates of our 2SLS (equation 2). Columns 1 and 2 restrict the sample to swing and non-swing states using the list of swing states listed in the PAP. Columns 3 and 4 restrict the sample to swing and non-swing states using the list of swing states listed in the paper. The variables of interest are the cumulative number of COVID-19 cases per 10,000 (Panel A) and COVID-19 deaths per 100,000 (Panel B), respectively. Demographic controls include population, female population share, foreign-born population, Non-Hispanic Black population, Non-Hispanic White population and the share of the population by age groups. Socioeconomic controls include: share of the population with a college degree and four occupational indexes. Standard errors clustered by state in parentheses $* * * \mathrm{p}<0.01, * * \mathrm{p}<0.05, * \mathrm{p}<0.1$. 
Panel A: First Stage

Cumulative COVID Cases

(4)

(5)

(6)

Share Workers

$371.17^{* * *}$

$327.06^{* * *}$

$318.03^{* * *}$

Meat Plants

(87.92)

$(84.82)$

$(81.85)$

Panel B: OLS and 2SLS

Change in Total Votes

from 2016 to 2020

(1)

$-6.202$

(2)

(3)

$-6.307$

(4.467)

$-6.903$

(4.693)

31.92

(21.65)

(4)

(5)

(6)

Cumulative COVID
Cases per 10,000

Unemp. Change

$-994$

(680)
$37.55^{*}$

(21.88)

30.59

$-811$

(656)

\begin{tabular}{lcccccc} 
State FE & Yes & Yes & Yes & Yes & Yes & Yes \\
Share Manufacturing & & & & Yes & Yes & Yes \\
Demo. Controls & Yes & Yes & Yes & Yes & Yes & Yes \\
Socioecon. Controls & Yes & Yes & Yes & Yes & Yes & Yes \\
Social Distancing & & Yes & Yes & & Yes & Yes \\
Observations & 2,586 & 2,586 & 2,586 & 2,586 & 2,586 & 2,586 \\
F-Statistics & & & 72.10 & 55.03 & 51.34 \\
\hline \hline
\end{tabular}

Notes: Election data from Dave Leip's Atlas of US Presidential Elections. An observation is a county. Robust standard errors are in parentheses, adjusted for clustering by state. We present OLS estimates in columns 1-3 of specification 1. We present the first stage (Panel A) and the 2-stage estimates (Panel B) of specification (2) in columns 4-6 in which we instrument COVID-19 incidence in a first stage by the share of employment in processing meat factories. In Panel A, the dependent variable is the cumulative number of COVID-19 cases per 10,000 (columns 4-6). In Panel B, the dependent variable is the differential in total votes from 2016 to 2020. Demographic controls include population, female population share, foreign-born population, non-Hispanic Black population, non-Hispanic White population and the share of the population by age group. Socioeconomic controls include: share of the population with a college degree and four occupational indexes. The Unemployment change variable is the unemployment rate as of September 2020 minus the unemployment rate as of September 2019. Standard errors clustered by state in parentheses $* * * \mathrm{p}<0.01, * * \mathrm{p}<0.05, *$ $\mathrm{p}<0.1$. 